\title{
A relação entre bem-estar e resiliência na habitação social: um estudo sobre os impactos existentes
}

\author{
The relationshipbetweenwellbeingandresilience in social \\ housing: a studyonexistingimpacts
}

\section{Geovanna Moreira Araujo \\ Simone Barbosa Villa}

\section{Resumo}

A

S habitações entregues pelos programas governamentais apresentam grandes limitações de sua qualidade arquitetônica e urbanística, atendendo de maneira mínima as necessidades básicas dos usuários, gerando uma negativa noção de bem-estar. Além disso, tais habitações respondem de forma precária aos diversos impactos sofridose não promove uma adaptação positiva nos espaços da unidade habitacional. O estudo desses fenômenos e a proposição de caminhos para sua melhoria têm demonstrado haver uma lacuna do conhecimento, a qualpretendemos preencher. Nesse cenário, o trabalho tem por objetivo principal investigar a relação entre a resiliência no ambiente construído e o bem-estar dos moradores em HIS sob a ótica do Five Ways to Wellbeing, disponibilizando soluções e estratégias para sua obtenção orientadas aos usuários. Para isso, foi elaborado um instrumento de avaliação pósocupação por meio de ferramenta computacional, aplicados em dois estudo de caso na cidade de Uberlândia. Este artigo apresenta parte dos resultados do trabalho, focando na sua fundamentação teórica, definição de indicadores de bem-estar e avaliação de impactos percebidos em um estudo de caso. As principais contribuições dos resultados parciais para o conhecimento científico sobre o tema demonstram a relação direta entre a resiliência e o bem-estar, além da constatação de que os impactos incidentes nos ambientes estudados são frequentes, indicando a baixa resiliência do ambiente construído.

Palavras-chave: Resiliência. Bem-estar. Impactos. Habitação social. Avaliação pósocupação.
Abstract
The homesdelivered by government programs have greatlimitations on theirarchitectural and urban quality, meeting the basicneeds of users in a minimal way, generating a negative sense of well-being. In addition,
suchdwellingsrespondpoorly to the variousimpactssuffered and do not promote a positive adaptation in the spaces of the housing unit. The study of thesephenomena and the proposal of ways to improvethem have shownthatthere is a knowledgegap, whichweintend to fill. In this scenario, the mainobjective of the work is to investigate the relationshipbetweenresilience in the builtenvironment and the well- being of residents in HIS from the perspective of FiveWays to Wellbeing, providing
solutions and strategies for obtaining it oriented to users. For this, a post- occupationassessment instrument wasdevelopedusing a computationaltool, applied in two case studies in the city of Uberlândia. This article presents part of the results of the work, focusing on itstheoreticalfoundation, definition of well- beingindicators and assessment of perceivedimpacts in a case study. The maincontributions of partialresults to scientificknowledge on the subjectdemonstrate the directrelationshipbetweenresilience and well-being, in addition to the findingthat the impacts on the studiedenvironmentsarefrequent, indicating the lowresilience of the builtenvironment.
Keywords: Resilience. Wellbeing. Impacts. Social housing. Post-occupation evaluation.

${ }^{1}$ Geovanna Moreira Araujo 1 Universidade Federal de Uberlândia Uberlândia - MG - Brasil

${ }^{2}$ Simone Barbosa Villa ${ }^{2}$ Universidade Federal de Uberlândia Uberlândia - MG - Brasil

Recebido em 06/12/19 Aceito em 26/03/20 


\section{Introdução}

Pesquisas recentes têm demostrado que as unidades habitacionais sociais entregues pelos programas governamentais brasileiros atendem de forma precária as amplas e variadas necessidades básicas dos usuários, ocasionando uma negativa noção de bem-estar (AMORE; SHIMBO; RUFINO, 2015; ANGÉLIL; HEHL, 2014; VILLA; SARAMAGO; GARCIA, 2015; VILLA; ORNSTEIN, 2013).

Diante disso, torna-se relevante promover habitações dotadas de qualidades mínimas necessárias relacionadas à resiliência, a partir de estratégias que favorecem o bem-estar em HIS. Para se chegar a essas estratégias procura-se investigar e analisar os impactos existentes no estudo de caso adaptando os parâmetros do "Five Ways to Wellbeing" (5W) à realidade brasileira. Tal modelo, desenvolvido originalmente pelo governo britânico, consiste em cinco caminhos para o bem-estar, estabelecidos a partir de evidências analisadas na vida da população britânica e amplamente testada e aplicada em mais de 50 países. Nesse sentido, procuramos adotar essa metodologia consolidada adaptando-a para o cenário brasileiro.

Esses 5W são ações acessíveis para o indivíduo melhorar seu bem-estar pessoal e comportamentos que podem ser utilizados por comunidades, organizações e poderes políticos para ajudar, apoiar e melhorar a qualidade de vida dos indivíduos. As ações consistem em: conectar, continuar aprendendo, tomar conhecimento, ser ativo e doar. Entende-se que promover espaços que facilitem o desenvolvimento dos $5 \mathrm{~W}$ gera o bem-estar de seus usuários, contribuindo para um ambiente mais resiliente (AKED; THOMPSON, 2011; BAKER; STEEMERS, 2019).

O presente artigo deriva da pesquisa de mestrado em andamento no Programa de Pós-Gradução em Arquitetura e Urbanismo, da Universidade Federal de Uberlândia ${ }^{1}$, intitulada "Bem-estar e resiliência em habitação social: uma relação necessária - estratégias para sua obtenção orientadas aos usuários", que tem por objetivo principal investigar a relação entre a resiliência no ambiente construído e o bem-estar dos moradores em HIS sob a ótica do 5W, disponibilizando soluções e estratégias para sua obtenção orientadas aos usuários. Essa pesquisa de mestrado se insere em um projeto maior, intitulado "[BER_HOME] Resiliência no ambiente construído em habitação social: métodos de avaliação tecnologicamente avançados",

A pesquisa maior tem como objetivo principal avaliar os fatores que constituem a resiliência no ambiente construído em habitação social, identificando os principais atributos projetuais que lhe conferem resiliência. Desta forma, a pesquisa geral chegou a uma matriz de seis atributos facilitadores da resiliência em HIS: adequação ambiental, adequação climática, flexibilidade, acessibilidade, engajamento e bem-estar. O atributo bem-estar é o foco desta pesquisa de mestrado, que tem como objetivo principal aprofundar seus conceitos e indicadores.

O estudo em desenvolvimento se diferencia também na medida em que foca no usuário/morador de HIS, tanto porque busca compreender os principais impactos, vulnerabilidades e capacidades adaptativas sob a percepção do morador, como pretende ofertar em ambientes Web/aplicativos, informações e estratégias orientadas a esses usuários afim de ampliar de forma prática, definitiva e direta a resiliência no ambiente construído e o bem-estar.

Tais encaminhamentos se baseiam principalmente na constatação de quatro dados centrais:

(a) a grande maioria das pesquisas realizadas na área de HIS é de natureza predominantemente descritiva e, apesar de seu número, relevância e expressividade, têm contribuído pouco para uma mudança da qualidade dos projetos de tais empreendimentos, notadamente do PMCMV (KOWALTOWISKI et al., 2019);

(b) o número de unidades habitacionais produzidas pelo PMCMV até o momento é expressivo, alcançando atualmente a marca de aproximadamente 5 milhões - universo esse que precisa ser enfrentado e qualificado (BIDERMAN et al., 2019);

\footnotetext{
1Programa de Pós-Graduação da Faculdade de Arquitetura e Urbanismos e Design. Disponível em: http://www.ppgau. faued.ufu.br.

${ }^{2}$ Pesquisa desenvolvida no [MORA] pesquisa em habitação da Universidade Federal de Uberlândia - Faculdade de Arquitetura e Urbanismo e Design (FAUeD/UFU). Disponívelem: https://morahabitacao.com/pesquisas-em-andamento2/ber_home-resiliencia-no-ambiente-construido-em-habitacao-social-metodos-de-avaliacao-tecnologicamenteavancados/.
}

142 Araujo, G. M.; Villa, S. B. 
(c) atualmente o número de aparelhos celulares é maior que o número de habitantes no Brasil, significando que a grande totalidade da população tem acesso à Internet e portanto pode se beneficiar de conteúdos orientados nesse ambiente (IBGE..., 2017; ÉPOCA..., 2019); e

(d) há uma carência grande de dados, estratégias e informações que possam assistir tecnicamente os usuários nas intervenções realizadas nas moradias (KOWALTOWISKI et al., 2018).

Para alcançar os objetivos da pesquisa, foram elaborados instrumentos de avaliação pós-ocupação por meio de ferramentas computacionais, que preconizam o uso de aplicativos e/ou página na Web, aplicados em dois estudo de caso na cidade de Uberlândia.

Este artigo apresenta parte dos resultados do trabalho focando na sua fundamentação teórica, definição de indicadores de bem-estar e avaliação de impactos percebidos em um estudo de caso.

\section{Referencial teórico}

Os modelos de habitação social, recentemente ofertados pelos programas habitacionais governamentais no Brasil, encontram-se em um cenário de grandes limitações de sua qualidade arquitetônica e urbanística. Essas observações tornam-se notáveis no programa de habitação do governo federal: Programa Minha Casa Minha Vida (PMCMV), implantado no país em 2009. Tal programa, nos últimos dez anos, tornou-se alvo de inúmeras pesquisas que visam suas melhorias. Várias dessas pesquisas têm demostrado que as unidades habitacionais disponibilizadas, independentemente do local que se inserem, atendem de forma precária as amplas e variadas necessidades básicas de seus usuários (BIRDEMAN et al., 2019; AMORE; SHIMBO; RUFINO, 2015; ANGÉLI; HEHL, 2014; ORNSTEIN; VILLA, 2013), ocasionando uma negativa noção de bem-estar. Também, tais empreendimentos têm demostrado pouca resiliência, já que seus ambientes construídos absorvem e respondem de maneira mínima aos impactos sofridos, além de não promoverem uma adaptação positiva dos espaços. Muitas vezes essas adaptações, feitas pelos próprios usuários de forma não orientada por um profissional, acabam prejudicando seu conforto, segurança, saúde e tranquilidade de tal forma que acabam prejudicando diretamente o bem-estar dos moradores.

Nesse contexto de adequações informais, notamos que as cidades enfrentam uma série de diversidades e desafios crescentes, que vão desde os efeitos das mudanças climáticas, até as alterações de perfis familiares da população. Assim, entende-se a resiliência como uma qualidade do ambiente construído que amplia fortemente sua capacidade de se adaptar e se transformar frente aos desafios impostos, auxiliando-o a ser mais potente à prova de futuro.

O termo resiliência surgiu na década de 1970, na área da ecologia, o que gerou comprometidos debates entre economistas, engenheiros, psicólogos dentre outros especialistas. O termo surge da palavra latina resilio, que significa "a capacidade de se recuperar". Como conceito acadêmico, suas origens e significado são mais ambíguos (MEEROW; NEWELL, 2015). De acordo com Holling (1973), ecólogo, que é um dos primeiros teóricos a falar sobre o termo, há duas principais definições. Uma mais tradicional focada na eficiência, constância e previsibilidade como atributos desejáveis na engenharia e à prova de falhas. Já a segunda definição refere-se a um sistema no qual instabilidades alteram completamente seu regime de operação rumo a um novo domínio de estabilidade. Nesse caso a resiliência é definida pela qualidade de distúrbios que um sistema pode absorver antes de se transformar e ser capaz de lidar com a nova situação colocada (HOLLING, 1973). A variedade do termo pode ser benéfica ao permitir seu funcionamento como um conceito aplicável a múltiplos contextos sociais, capaz, portanto, de promover a colaboração cientifica multidisciplinar.

Nos últimos anos o termo "resiliência" ganhou grande visibilidade no meio acadêmico e em discursos políticos devido ao seu apelo revolucionário, ao oferecer uma alternativa ao atual modelo de produção social. À medida que as cidades continuam a crescer e a lidar com incertezas e desafios, como a mudança climática e as instabilidades econômicas e sociais, a resiliência urbana torna-se um conceito cada vez mais atraente (GARCIA; VALE, 2017).

No contexto desta pesquisa, entende-se por resiliência, no âmbito do ambiente construído, como sua capacidade de absorver, se adaptar e se transformar positivamente para lidar com as mudanças e os impactos sofridos ao longo do tempo (GARCIA; VALE, 2017; PICKETT; CADENASSO; FELSON, 2014; MAGUIRE; CARTWRIGHT, 2008).

O fato de existirem inúmeras estratégias relacionadas a diferentes configurações do espaço e de usuários é importante para que o ambiente construído seja resiliente. Isso é particularmente importante em um contexto 
de grandes mudanças demográficas, climáticas, de estilo de vida e de disponibilidade de novas tecnologias. $\mathrm{O}$ ambiente construído deve responder às necessidades, aos comportamentos e aos desejos dos usuários, oferecendo, assim, liberdade de escolha e controle sobre estes (STEEMERS, 2015).

A resiliência também pode ser entendida como o estado contrário à vulnerabilidade (INTERGOVERNMENTAL..., 2014). A vulnerabilidade refere-se à sensibilidade do sistema diante de ameaças especificas, combinadas com a capacidade adaptativa da população, das instituições expostas e do ambiente construído, ou seja, suas condições de utilizar os recursos disponíveis para reagir aos eventos. Segundo Lemos (2014), a pobreza e a desigualdade são os fatores mais negativos que mais impactam na vulnerabilidade. As áreas de pobreza urbana, assim como as moradias sociais, são áreas com sérias deficiências, em relação aos aspectos físicos - infraestrutura, serviços, qualidade construídas e ambientais, entre outros. No que se refere a aspectos sociais e econômicos do sistema urbano são áreas que concentram população com baixa escolaridade e baixa renda familiar, falta de autonomia local e, muitas vezes, um ambiente de violência com pouca intervenção do poder público. Percebe-se que tal modelo de urbanização apresenta características problemáticas, como um metabolismo desiquilibrado.

Segundo Fenton et al. (2007), existem várias maneiras de caracterizar a vulnerabilidade:

(a) vulnerabilidade a um perigo;

(b) vulnerabilidade como um "estado"; e

(c) vulnerabilidade como componente de uma comunidade.

A vulnerabilidade em unidades habitacionais de interesse social refere-se ao seu estado de sensibilidade/susceptibilidade a determinadas ameaças, derivando, principalmente, de características inerentes ao projeto entregue (cenário 1) e da situação da edificação no momento da incidência dessas ameaças (cenário 2), que comprometem sua capacidade de resistir, adaptar-se e transformar-se. A partir desse entendimento, importa salientar que características construtivas não são ameaças (choques agudos ou estresses crônicos), mas, sim, vulnerabilidades (VILLA et al., 2017).

Já a capacidade adaptativa, conceito intimamente ligado àresiliência (MAGUIRE; CARTWRIGHT, 2008), é definida como "[...] a capacidade de um sistema de modificar ou alterar suas características ou comportamentos para lidar com tensões reais ou previstas [...]” (BROOKS, 2003, p.8). A capacidade adaptativa está relacionada ao conceito de adaptação. Adaptação inclui ações tomadas para reduzir a vulnerabilidade e aumentar a resiliência, e capacidade adaptativa é a capacidade de tomar essas ações.

Pode-se entender assim que capacidade adaptativa e vulnerabilidade estão relacionadas diretamente à resiliência. Onde há alta capacidade adaptativa e baixa vulnerabilidade reconhece-se um sistema ou ambiente construído mais resiliente (Figura 1). Nesse sentido reforça-se a teoria de que a resiliência é uma habilidade do sistema em modificar-se e articular-se para lidar com impactos (absorvendo, adaptando e/ou transformando-se), demonstrando sua capacidade adaptativa.

Por outro lado, a deterioração do sistema quando exposto a determinados impactos caracteriza um estado de vulnerabilidade. Afinal uma cidade precisa ser resiliente em todas as escalas, com propósito de evitar colapsos quando exposta às mudanças inesperadas e/ou impostas pela ação humana. Dessa forma, entendese colapsos como a perda indesejável de sua funcionalidade, estrutura e identidade (GARCIA; VALE, 2017).

Os impactos impostos à sociedade pelas características de um sistema de urbanização desiquilibrado fragilizam socialmente, economicamente e ambientalmente a população beneficiada pelos programas sociais, tornando-as, em certa medida, mais vulneráveis aos impactos imprevistos.

Todos esses impactos podem ser caracterizados em diferentes tipos:

(a) ordem natural climática: chuvas muito fortes que podem causar danos nas casas ou mesmo inundações, seca por períodos longos;

(b) ordem física-arquitetônica: nas casas a precariedade dos materiais de construção empregados, assim como sua padronização de programas e sua limitada área útil, a ausência de equipamentos adequados para controle e estanqueidade, a precariedade das instalações elétricas e hidrossanitárias;

(c) ordem física-urbanística: a baixa densidade, a monotonia tipológica, a ausência de infraestrutura adequada dos conjuntos habitacionais implantados, a ausência de equipamentos adequados de lazer, cultura, educação, saúde e segurança para seus moradores, a limitação dos transportes públicos; e 
(d) ordem socioeconômica: a falta de oportunidades no bairro de emprego e serviços, em geral (VILLA et al., 2017).

Para aprimorar a resiliência em um sistema é necessário saber inicialmente quais impactos incidem sobre o ambiente - o que implica medir algo. Posteriormente sugere-se identificar aonde se deseja chegar, ou seja, quais estratégias poderão ser adotadas no sentido de ampliar sua resiliência, o que implica traçar possibilidades (GARCIA; VALE, 2017). Nesse sentido identificar quais são as ameaças incidentes, encontrar o que está exposto (material e população) e a vulnerabilidade específica local é o primeiro passo para determinar as ações adaptativas que visam à resiliência em um sistema urbano. Assim, importa conhecer os impactos que incidem sobre o sistema, observando sua repercussão sobre o conjunto, e se origina "capacidade adaptativa" ou "vulnerabilidade". A partir disso, serão traçados objetivos para amenizar a vulnerabilidade e potencializar a capacidade adaptativa.

O termo impacto refere-se ao conjunto de choques agudos e/ou estresses crônicos que ameaçam vidas, meios de subsistência, saúde, ecossistemas, economias, culturas, serviços e infraestrutura de uma sociedade e ambiente construído expostos, gerando efeitos negativos proporcionais ao seu estado de vulnerabilidade em um dado momento (Quadro 1). Os impactos incidentes sobre o urbano e seus sistemas são causados, $a$ priori, por grandes eventos ou desafios globais, com os quais os governos e a sociedade como um todo têm se deparado contemporaneamente, chamando para si grande atenção. Motivam, ao redor de todo o mundo, pesquisas que visam ao seu enfrentamento e à minimização de seus efeitos negativos sobre os ambientes natural e construído (ARUP; THE ROCKEFELLER..., 2015; GARCIA; VALE, 2017; ELIASTROSTMANN et al. 2018; LEMOS, 2014).

Evidentemente, torna-se importante promover um ambiente construído com qualidades mínimas relacionadas à resiliência, a partir de estratégias que favorecem o bem-estar em HIS, e entende-se que a resiliência física do ambiente construído promove e facilita o aumente do bem-estar dos usuários (STEEMERS, 2015; BAKER; STEEMERS, 2019; GARCIA; VALE, 2017; WHEELER; HUGGETT; ALKER, 2016).

Figura 1 - Diagrama sobre como ocorre o aumento da resiliência
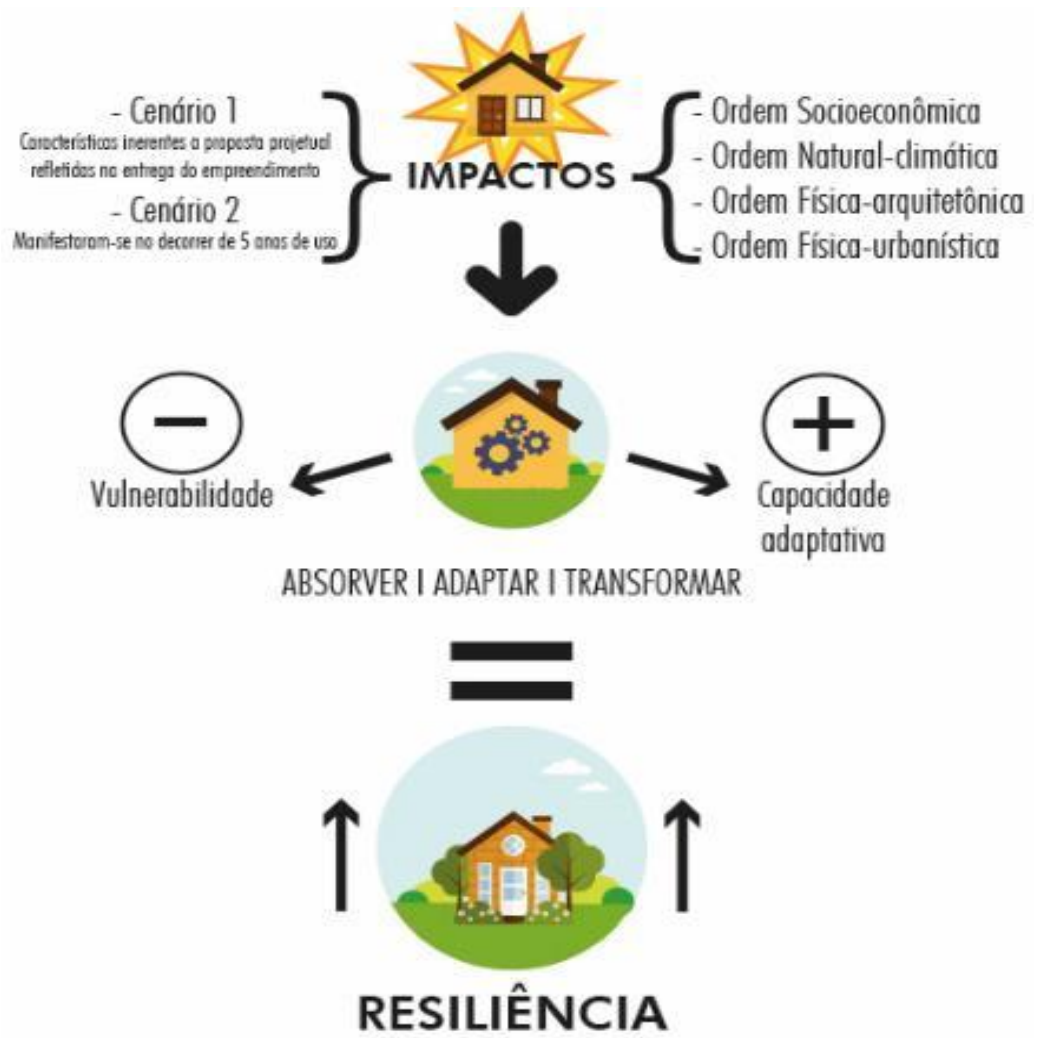
Quadro 1 - Quadro de conceito do termo impacto

\begin{tabular}{|c|c|c|}
\hline \multicolumn{3}{|r|}{ IMPACTOS SOBRE O AMBIENTE CONSTRUIDO DERIVA DE: } \\
\hline \multicolumn{2}{|c|}{$\begin{array}{l}\text { CAUSAS } \\
\text { (Grandes eventos) }\end{array}$} & $\begin{array}{l}\text { Origem, motivo ou razão para que algo aconteça (dicionário). Refere-se a } \\
\text { grandes eventos decorridos no tempo e no espaço que fazem parte da vida no } \\
\text { planeta Terra (GARCIA; VALE, 2017). Podem ser de ordem climática, } \\
\text { ambiental, social, econômica e/ou política. }\end{array}$ \\
\hline \multirow{3}{*}{ 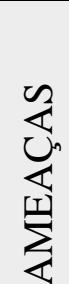 } & \multicolumn{2}{|c|}{$\begin{array}{l}\text { Ameaças referem-se aos fenômenos climáticos, ambientais, sociais, econômicos e/ou políticos } \\
\text { incidentes sobre o urbano capazes de gerar efeitos sensíveis sobre o ambiente construído das } \\
\text { unidades habitacionais, na medida de sua vulnerabilidade. Podem classificar-se como: }\end{array}$} \\
\hline & $\begin{array}{l}\text { CHOQUES } \\
\text { AGUDOS }\end{array}$ & $\begin{array}{l}\text { Choques repentinos, derivados de eventos agudos que ameaçam uma cidade } \\
\text { (ARUP; THE ROCKEFELLER..., 2015). }\end{array}$ \\
\hline & $\begin{array}{l}\text { ESTRESSES } \\
\text { CRÔNICOS }\end{array}$ & $\begin{array}{l}\text { Desastres lentos que enfraquecem o tecido de uma cidade (ARUP ;THE } \\
\text { ROCKEFELLER..., 2015). }\end{array}$ \\
\hline \multicolumn{2}{|c|}{$\begin{array}{l}\text { EFEITOS } \\
\text { NEGATIVOS }\end{array}$} & $\begin{array}{l}\text { Prejuízos sofridos ou causados por algo ou alguém (ex.: danos físicos, morais, } \\
\text { patrimoniais) (dicionário). Mais especificamente, referem-se às consequências } \\
\text { negativas das ameaças incidentes sobre bens e pessoas, que geram patologias no } \\
\text { ambiente construído e enfraquecem laços sociais e afetivos entre moradores e } \\
\text { entre estes e o ambiente construído que ocupam. No contexto do ambiente } \\
\text { construído de unidades habitacionais de interesse social, podem ser percebidos } \\
\text { nas escalas do terreno, da estrutura, das vedações verticais e horizontais, das } \\
\text { infraestruturas, dos ambientes e mobiliários (BRAND, 1994). Sua extensão } \\
\text { deriva da e amplifica a sensibilidade/susceptibilidade do ambiente construído } \\
\text { sob ameaças, ou seja, sua vulnerabilidade. }\end{array}$ \\
\hline
\end{tabular}

A noção de bem-estar consiste em dois elementos fundamentais: sentir-se bem e funcionar bem. Sentimentos de felicidade, curiosidade e envolvimentos são características de uma pessoa com um senso positivo de si mesmo. Ter relacionamentos positivos, ter controle da sua própria vida e um senso de propósitos são todos atributos de um bom funcionamento (STEEMERS, 2015). O significado de bem-estar está relacionado diretamente ao estado do indivíduo. É um conjunto de práticas que englobam boa nutrição, atividade física, bons relacionamentos interpessoais, familiares e sociais, além de controle do estresse. Pode-se assim dizer que bem-estar significa a saúde no seu sentido mais amplo, de maneira ativa e em todos os seus aspectos.

O termo "bem-estar" aparece pela primeira vez, no século XVI, para designar a satisfação de necessidades físicas, enquanto no século XVIII ele se refere à situação material que permite satisfazer as necessidades da existência.Esse termo está diretamente ligado à saúde, definida pela Organização Mundial da Saúde não apenas como ausência de problemas de saúde, mas como “[...] um estado de completo bem-estar físico, mental e social [...]". Por isso, interpretamos "bem-estar" para incluir fatores sociais, psicológicos e físicos (WHEELER; HUGGETT; ALKER, 2016).

É importante notar que a saúde e o bem-estar são influenciados por uma combinação complexa de fatores genéticos, comportamentais e ambientais. O ambiente construído e os profissionais que trabalham nesse setor não têm influência sobre todos esses fatores, mas desempenham um papel crucial. A qualidade do espaço construído e a forma com que ele permite adaptações e transformações de acordo com a necessidade dos seus usuários, ou seja, ambientes resilientes, podem e devem permitir o bem-estar destes.

$\mathrm{O}$ ambiente em que vivemos afeta o nosso bem-estar, o que pode levar a implicações de longo prazo em nossa qualidade de vida. Segundo Thaler e Sunstein (2008) o comportamento humano pode ser influenciado pelo contexto em que somos inseridos, no qual o ambiente construído pode facilitar ou dificultar as escolhas, comportamentos e ações.

Para realmente melhorar o bem-estar, o ambiente construído precisa possuir além da otimização de parâmetros, como regras estipuladas por normas. O ambiente construído requeruma abordagem mais holística e ampla, pensando nos comportamentos e sentimentos humanos. Uma abordagem que procura e determina estratégias que aumente a diversidade e a adaptabilidade, e que sejam centradas nas reais necessidades dos usuários (STEEMERS, 2015; BAKER; STEEMERS, 2019).

Pesquisas no campo da saúde têm demostrado, segundo Steemers (2015), que o ambiente construído tem grandes impactos no bem-estar físico e mental das pessoas. Esses impactos podem ser de forma direta (consequências na saúde física e mental) ou indireta (consequências através de mecanismos sociais). 
Pensando nesses argumentos, vê-se a possibilidade da aplicação dos parâmetros do 5W (Figura 2) à realidade brasileira, uma vez que consiste em ações de fácil acesso e desenvolvimento por parte dos usuários. A abordagem $5 \mathrm{~W}$ foi adotada internacionalmente como intervenções downstream (nível individual) e/ou upstream (nível de ambiente), em países como Austrália, Croácia, Holanda, Islândia, Irlanda, Japão, Nova Zelândia, Noruega, Reino Unido e Estados Unidos, e foram traduzidos para outras seis línguas (ANDERSON et al., 2016). Intervenções downstream consistem em motivar os indivíduos a fazerem mudanças por sua própria vontade. Já as intervenções upstream é sobre mudar o ambiente em que os comportamentos ocorrem, promovendo novas alternativas. Isso pode significar entender os padrões de escolhas e fornece novas estratégias que facilite ou crie barreiras de modo a encorajar comportamentos mais positivos (AKED; THOMPSON, 2011).

As ações descritas a seguir caracterizam os $5 \mathrm{~W}$ e são analisadas de forma que o ambiente construído possa influenciar no bem-estar de forma positiva.

(a) conectar: esse indicador pode ser percebido nas formas como o ambiente contribui para o desenvolvimento de relacionamentos, locais que criam oportunidades de as pessoas se conectarem, como, por exemplo, espaços com fácil acesso e com proximidade de equipamentos públicos e de uso comum (escolas, mercados, entre outros) e que apoiam encontros casuais.

(b) continuar aprendendo: esse indicador entende que o ambiente físico do lar e da escala urbana possuem grande influência no desenvolvimento intelectual de seu usuário. O ambiente construído precisa ser confortável fisicamente, seguro, iluminado, silencioso e apresentar boa circulação de ar (STEEMERS, 2015).

(c) tomar conhecimento: nesse indicador o ambiente construído pode fornecer espaços expositivos, áreas de contemplação - paisagismo, bancos, entre outras estratégias arquitetônicas - que possibilitem a observação significativa das pessoas, fazendo-as parar e prestar atenção ao seu redor (STEEMERS, 2015).

(d) ser ativo: esse indicador apresenta as características de projeto associadas ao aumento de atividades físicas que incluem, por exemplo, acesso a instalações esportivas, calçadas arborizadas confortáveis para o desenvolvimento de caminhadas. No ambiente construído interno o desenvolvimento de espaços que possibilitem o exercício físico pode ser feito de forma simples, como circulações adequadas, ambientes em diferentes níveis com o uso de escadas, por exemplo (STEEMERS, 2015).

(e) doar: é entendido como um sentimento altruísta, em ser educado, ajudar o próximo. Há evidências de que as pessoas são menos altruístas em ambientes urbanos do que nos rurais, o que confirma que o contato com espaços verdes e a interação com a natureza são valiosos (STEEMERS, 2015). Por isso a necessidade de desenvolver ambientes com características físicas positivas, como diversidade de usos, fáceis acessos, acessibilidade e qualidade espacial e visual.

Não existem soluções universais para garantir que todos os parâmetros de bem-estar sejam desenvolvidos e otimizados, porém os profissionais da área no mínimo devem garantir que as estratégias projetuais que facilitam e promovem o bem-estar alcancem níveis satisfatórios e relativamente bons, sem afetar e impactar negativamente a qualidade de vida dos usuários (STEEMERS, 2015). Para isso foram idealizados subindicadores destacados no Quadro 2 correspondentes a cada indicador de bem-estar. Tais subindicadores têm como objetivo fornecer estratégias arquitetônicas específicas nas unidades habitacionais de modo a favorecer o bem-estar dos moradores.

\section{Método}

Os procedimentos metodológicos utilizados na pesquisa foram:

(a) pesquisa bibliográfica: estudo acerca do tema bem-estar e resiliência no ambiente construído em fontes primárias e secundárias;

(b) pesquisa referencial: levantamento por meio dos resultados de outras análises semelhantes e coleta de dados;

(c) pesquisa conceitual-abstrata: apresentação do conceito e teorias pretendidos e desenvolvimento dos instrumentos de avaliação e análise;

(d) pesquisa empírica: estudo observacional e aplicação da avaliação pós-ocupação e análise comparativa de dois estudos de caso - um conjunto do PMCMV de casas térreas e outro de apartamentos- localizados em Uberlândia; e 
(e) pesquisa propositiva:desenvolvimento de soluções e estratégias para a obtenção do bem-estar (5W) e da resiliência orientadas ao usuário-morador a fim de promover uma real mudança em sua qualidade de vida.

Tais soluções serão disponibilizadas em ambiente Web (aplicativo e/ou página).

A presente pesquisa baseia-se no método conhecido como design scienceresearch (DSR) (DRESCH; LACERDA; JUNIOR, 2015). Esse método consiste em procurar consolidar conhecimento sobre o projeto e desenvolvimento de solução para melhorar sistemas existentes, resolvendo problemas e criando artefatos (algo que é construído, interface entre ambiente interno e o ambiente externo de um determinado sistema).

Figura 2 - Five waystowellbeing
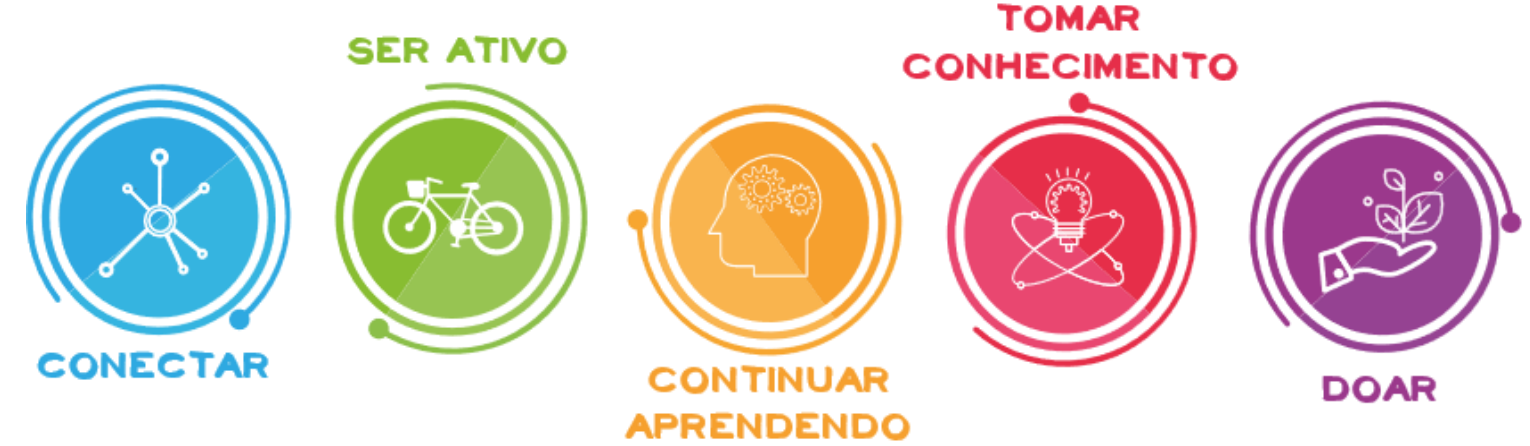

Quadro 2 - Indicadores do bem-estar baseado nos $5 \mathrm{~W}$ adaptados à realidade brasileira

\begin{tabular}{|c|c|c|}
\hline ATRIBUTO & INDICADORES & SUB-INDICADORES \\
\hline \multirow{25}{*}{ BEM-ESTAR } & \multirow{5}{*}{$\begin{array}{l}\text { CONECTAR } \\
\text { é sobre conectar com as pessoas, } \\
\text { relacionamentos com vizinhos, } \\
\text { familiares e amigos. }\end{array}$} & Acesso de serviços locais \\
\hline & & Espaços para desenvolvimento de atividades \\
\hline & & Áreas adequadas para interação \\
\hline & & Ambientes adaptáveis \\
\hline & & Privacidade \\
\hline & \multirow{3}{*}{$\begin{array}{c}\text { SER ATIVO } \\
\text { é sobre desenvolvimento de } \\
\text { atividades físicas, seja correr, andar } \\
\text { de bicicleta, praticar um esporte, } \\
\text { dançar. }\end{array}$} & Espaços públicos de usos diversos \\
\hline & & Fácil acesso a espaços públicos \\
\hline & & Quadras poliesportivas, playgrounds \\
\hline & \multirow{8}{*}{$\begin{array}{l}\text { CONTINUAR APRENDENDO } \\
\text { é sobre aprender coisas novas, seja } \\
\text { aprender a tocar um instrumento } \\
\text { musical, aprender sobre jardinagem, } \\
\text { culinária, entre outros. }\end{array}$} & Espaços de usos diversos (pomares, hortas, etc.) \\
\hline & & Acesso fácil a instituições de ensino \\
\hline & & Espaços calmos e silenciosos \\
\hline & & Locais de uso público para aprendizagem \\
\hline & & Escolas locais \\
\hline & & Ambientes adaptáveis \\
\hline & & Boa acústica, iluminação, ventilação \\
\hline & & Limpeza \\
\hline & \multirow{3}{*}{$\begin{array}{l}\text { TOMAR CONHECIMENTO } \\
\text { é sobre ter consciência das coisas ao } \\
\text { seu redor, dos sentimentos, } \\
\text { autoconhecimento. }\end{array}$} & Espaços públicos abertos (áreas verdes) \\
\hline & & Ambientes flexíveis, adaptáveis \\
\hline & & Privacidade \\
\hline & \multirow{6}{*}{$\begin{array}{l}\text { DOAR } \\
\text { é sobre ajudar o próximo, } \\
\text { voluntariar-se em projetos sociais } \\
\text { entre outras atividades. }\end{array}$} & Espaços públicos abertos \\
\hline & & Espaços adequados para receber visitas \\
\hline & & Ambientes de convívio \\
\hline & & Diversidade de usos \\
\hline & & Acessibilidade \\
\hline & & \\
\hline
\end{tabular}

148 Araujo, G. M.; Villa, S. B. 
A metodologia proposta procura reduzir a distância entre teoria e prática, mantendo o rigor necessário para garantir confiabilidade dos resultados das pesquisas. O principal objetivo do método é projetar e construir um artefato, prescrever soluções, estudar, pesquisar e investigar o artificial e seus comportamentos, de forma que esse artefato criado seja o produto final da pesquisa, podendo assim levar as soluções a gestores, empresas e até à própria comunidade (DRESCH; LACERDA; JUNIOR, 2015).

A avaliação pós-ocupação (APO) destaca-se como importante ferramenta na obtenção de dados consistentes relativos ao ambiente construído (ONO et al., 2018; VILLA; SARAMAGO; GARCIA, 2015; MALLORYHILL; PREISER; WATSON, 2012; COLE, 2005), da mesma maneira que na identificação de impactos em que o meio está sujeito, suas fragilidades, recursos e potencialidades. Sua utilização permite a montagem e observação, por parte dos agentes envolvidos, de bancos de dados alimentados por avaliações que incluam a percepção física do ambiente construído, além da interação entre esse ambiente e o comportamento dos usuários (STEVENSON, LEAMAN, 2010; VILLA; SARAMAGO; GARCIA, 2015).

Entender como se dá o movimento de adaptação no interior de um conjunto de habitações de interesse social, por meio de registros da APO, fornecerá ricos fundamentos para consulta e evolução do conceito de resiliência, abastecendo diversos atores sociais com material atual, confiável e pertinente para fundamentar seus empreendimentos.

Para a avaliação e análise do bem-estar da população, esta pesquisa pretende utilizar como parâmetro os $5 \mathrm{~W}$, estabelecido pelo governo britânico como um importante indicador de bem-estar da população no ambiente construído. Ter relações sociais fortes, sendo fisicamente ativo e estar envolvido na aprendizagem são todos importantes influenciadores para promover o bem-estar ou mal-estar (AKED; THOMPSON, 2011). Uma combinação de todos esses comportamentos ajuda a melhorar o bem-estar individual.

O estudo de caso escolhido para o desenvolvimento da pesquisa foram:

(a) um empreendimento horizontal do Programa Minha Casa Minha Vida, caracterizado por casas geminadas, denominado Residencial Sucesso Brasil - bairro Shopping Park; e

(b) empreendimento vertical do Programa Minha Casa Minha Vida, denominado Residencial Córrego do Óleo - loteamento 01 .

O método de trabalho aplicado na pesquisa foi:

(a) identificação do problema;

(b) revisão bibliográfica;

(c) identificação do artefato;

(d) desenvolvimento do artefato;

(e) aplicação do artefato em estudo de caso;

(f) conclusões; e

(g) comunicação dos resultados.

Como descrito no Quadro 3 a pesquisa utiliza-se de dois métodos para chegar ao principal objetivo: criação do questionário de IMPACTOS, o qual está sendo tratado neste artigo, e a régua de medição da resiliência e bem-estar. Este artigo trata somente sobre as etapas de identificação do problema, revisão bibliográfica, identificação do artefato, desenvolvimento do artefato e aplicação deste no estudo de caso.

Quadro 3 - Objetivos da pesquisa e métodos usados para alcançar cada objetivo

\begin{tabular}{|c|c|c|}
\hline Objetivo Principal & Objetivo Secundário & Método \\
\hline \multirow{3}{*}{$\begin{array}{l}\text { ARTEFATO interativo } \\
\text { direcionado aos usuários de HIS } \\
\text { com resultados da pesquisa e } \\
\text { estratégias e soluções } \\
\text { (assessoria técnica) que } \\
\text { aumente a resiliência física, } \\
\text { consequentemente aumentando } \\
\text { o bem-estar. }\end{array}$} & Identificação de Impactos & $\begin{array}{l}\text { Questionário - APO } \\
\text { (ONO et al., 2018) }\end{array}$ \\
\hline & $\begin{array}{l}\text { Identificação de adaptabilidades } \\
\text { e potencialidades }\end{array}$ & $\begin{array}{l}\text { Régua de medição de resiliência e } \\
\text { bem-estar } \\
\text { (BIDERMAN et al., 2019) }\end{array}$ \\
\hline & $\begin{array}{l}\text { Estratégias e soluções - } \\
\text { assessoria técnica direcionada } \\
\text { aos usuários e prestadores de } \\
\text { serviços }\end{array}$ & $\begin{array}{l}\text { Estudo de Caso (YIN, 2015) } \\
\text { Casos Controles (YIN, 2015; } \\
\text { BAKER; STEEMERS, 2019) }\end{array}$ \\
\hline
\end{tabular}




\section{Questionário de impactos}

Como abordado anteriormente, identificar quais são as ameaças incidentes, encontrar o que está exposto (material e população) e a vulnerabilidade específica local é o primeiro passo para determinar as ações adaptativas que visam à resiliência (GARCIA; VALE, 2017).

Entendido o conceito do termo impacto, abordado anteriormente, buscou-se identificar as ameaças presente no dia a dia dos moradores. Para isso desenvolveu-se um instrumento afim de constatar os efeitos negativos percebidos pelos moradores que interferem de forma negativa nos indicadores de bem-estar.

Tal instrumento consiste em um questionário voltado aos moradores das unidades habitacionais entregues pelo programa MCMV, investigando o nível de incômodo gerado a partir da percepção dos indivíduos ao longo do tempo de uso.

Uma pesquisa em APO tem como objetivo principal verificar o nível de satisfação do usuário com o ambiente construído durante o seu tempo de uso. Sendo assim o questionário é a ferramenta mais efetiva para atingir tal objetivo, uma vez que consiste em um instrumento para coleta de dados diretamente com o próprio usuário (ONO et al., 2018). Entendendo o principal objetivo da APO, o questionário foi elaborado em formato de perguntas estruturadas, ou seja, fechadas, pois possui uma ou mais alternativas, no qual o usuário respondente teria de escolher quais dos efeitos negativos - impactos - identificados por eles desde a entrega da casa até o presente momento, ou seja, impactos percebidos ao longo do tempo. Além de indicar o seu nível de incômodo gerado por tal problema (muito ou pouco).

O questionário foi dividido em três grandes eventos - causa: fatores socioeconômicos, modelo de implantação do PMCMV e implantação incompleta do PMCMV-geradores de ameaças e efeitos negativos, como apresentados nos Quadros 4, 5 e 6. A partir da separação dessas causas pode-se identificar as principais "ameaças" e quais eram os seus "efeitos negativos" - consequências - percebidos pelos usuários e se este gerava algum tipo de incômodo. Esse método usado para desenvolver o questionário chegou ao modelo apresentado pela Figura 3.

Quadro 4 - Impactos causados por fatores socioeconômicos

\begin{tabular}{|c|c|c|}
\hline \multicolumn{3}{|c|}{ CAUSA (GRANDE EVENTO): Fatores Socioeconômicos } \\
\hline AMEAÇAS & EFEITOS NEGATIVOS & INDICADORES para o Bem-estar \\
\hline $\begin{array}{l}\text { Desemprego e renda } \\
\text { insuficiente }\end{array}$ & $\begin{array}{l}\text { Dificuldades em juntar dinheiro para } \\
\text { gastos pessoais ou até necessários, } \\
\text { dificuldade de começar o próprio } \\
\text { negócio, interrupções de estudos, } \\
\text { surgimento de problemas familiares. }\end{array}$ & \\
\hline $\begin{array}{l}\text { Atentado de violência } \\
\text { repentina à domicilio }\end{array}$ & $\begin{array}{l}\text { Sensação de Insegurança, não } \\
\text { participação das atividades } \\
\text { desenvolvidas no bairro, deixa de } \\
\text { conviver com vizinhos, gastos } \\
\text { inesperados com medidas de } \\
\text { segurança. }\end{array}$ & \\
\hline Sensação de Insegurança & $\begin{array}{l}\text { Não participação das atividades no } \\
\text { bairro, não convivência com } \\
\text { vizinhos, não utilização das áreas de } \\
\text { lazer e locais públicos do bairro, } \\
\text { mantem a casa sempre fechada e } \\
\text { desenvolvimento problemas de saúde } \\
\text { (transtornos psicológicos). }\end{array}$ & \\
\hline Isolamento Social & $\begin{array}{l}\text { Não gosta de frequentar os espaços } \\
\text { públicos do bairro e acaba não } \\
\text { desenvolvendo vínculos com os } \\
\text { vizinhos. }\end{array}$ & \\
\hline
\end{tabular}

150 Araujo, G. M.; Villa, S. B. 
Quadro 5 - Impactos causados devido ao modelo de implantação do PMCMV

\begin{tabular}{|l|l|}
\hline \multicolumn{3}{|c|}{ CAUSA (GRANDE EVENTO): Modelo do PMCMV } \\
\hline \multicolumn{1}{|c|}{ AMEAÇAS } & \multicolumn{1}{c|}{ EFEITOS NEGATIVOS } \\
$\begin{array}{l}\text { Ambientes internos pequenos, } \\
\text { unidadião da área da } \\
\text { dificuldade de circulação pela casa, } \\
\text { dificuldade de mobiliar os ambientes, } \\
\text { falta de espaço para o desenvolvimento } \\
\text { de atividades domesticas e de lazer. }\end{array}$ \\
\hline $\begin{array}{l}\text { Dificuldade em se } \\
\text { adaptar a unidade } \\
\text { residencial }\end{array}$ & $\begin{array}{l}\text { Falta de identidade com a unidade } \\
\text { habitacional e até mesmo o próprio } \\
\text { bairro. }\end{array}$ \\
\hline $\begin{array}{l}\text { Sobreposição de } \\
\text { atividades em um mesmo } \\
\text { cômodo de forma } \\
\text { negativa. }\end{array}$ & $\begin{array}{l}\text { Falta de privacidade, dificuldade de } \\
\text { realizar atividades que gosta ou que } \\
\text { exige concentração, surgimento de } \\
\text { desentendimento entre os moradores. }\end{array}$ \\
\hline Baixo padrão construtivo & $\begin{array}{l}\text { Falta de privacidade entre os vizinhos, } \\
\text { má convivência, excesso de ruídos } \\
\text { externos dentro da casa, má qualidade } \\
\text { dos materiais gera reformas constantes. }\end{array}$ \\
\hline Localização periférica & $\begin{array}{l}\text { Falta de conexão com a cidade, } \\
\text { isolamento em relação as áreas da } \\
\text { cidade, dificuldade de deslocamento, } \\
\text { ausência de serviços e comércios } \\
\text { próximos. }\end{array}$ \\
\hline
\end{tabular}

Quadro 6 - Impactos causados devido à implantação incompleta do PMCMV

\begin{tabular}{|l|l|l|}
\hline \multicolumn{3}{|c|}{ CAUSA (GRANDE EVENTO): Aplicação Incompleta do PMCMV } \\
\hline \multicolumn{1}{|c|}{ AMEAÇAS } & \multicolumn{1}{c|}{ EFEITOS NEGATIVOS } \\
$\begin{array}{l}\text { Falta de qualidade nas } \\
\text { áreas públicas (ruas) } \\
\text { inexistência de ciclovias, ruas e } \\
\text { calçadas desconfortáveis para } \\
\text { caminhas, não apropriação dos espaços } \\
\text { da calçada e falta de arborização e } \\
\text { sombreamento. }\end{array}$ \\
$\begin{array}{l}\text { Iluminação Pública } \\
\text { insuficiente }\end{array}$ & $\begin{array}{l}\text { Gera insegurança, facilita assaltos, } \\
\text { pouca visibilidade durante a noite o } \\
\text { que acaba levando ao isolamento } \\
\text { dentro de casa. }\end{array}$ \\
\hline $\begin{array}{l}\text { Área de lazer } \\
\text { desqualificadas/ Falta de } \\
\text { equipamentos de lazer. } \\
\text { atividades ilícitas, não é convidativo ao } \\
\text { uso, acaba virando depósitos de lixo. } \\
\text { Não possui atividades atrativas, não } \\
\text { gera convívio no bairro. }\end{array}$ \\
\hline $\begin{array}{l}\text { Falta de equipamentos de } \\
\text { atenção a saúde }\end{array}$ & $\begin{array}{l}\text { Dificuldade de acesso, baixa qualidade } \\
\text { de atendimento e estrutura. }\end{array}$ \\
\hline $\begin{array}{l}\text { Falta de equipamentos de } \\
\text { ensino }\end{array}$ & $\begin{array}{l}\text { Dificuldade de acesso, baixa qualidade } \\
\text { de ensino, falta de investimento em } \\
\text { todos os níveis de escolaridade. }\end{array}$ \\
\hline
\end{tabular}


Figura 3 - Modelo de questionário desenvolvido

\begin{tabular}{|c|c|c|c|c|c|}
\hline \multicolumn{6}{|c|}{ CAUSA (GRANDE EVENTO): Fatores SocioeconômicOS } \\
\hline Ameaças & Efeitos Negativos sobre a casa e a família & \multicolumn{3}{|c|}{ Nível de incômodo } & Comentários \\
\hline \multirow{4}{*}{$\begin{array}{l}\text { ( ) Perda de emprego } \\
\text { (desemprego) }\end{array}$} & ( ) Renda familiar insuficiente & ( ) Pouco & ( ) Muito & () NA & \\
\hline & ( ) Não tem renda fixa & ( ) Pouco & ( ) Muito & ( ) NA & \\
\hline & ( ) Dificuldade em juntar dinheiro & ( ) Pouco & ( ) Muito & ( ) NA & \\
\hline & ( ) Dificuldade em arrumar um novo emprego & ( ) Pouco & ( ) Muito & ( ) NA & \\
\hline \multirow{4}{*}{ ( ) Renda insuficiente } & ( ) Dificuldade para montar seu próprio negócio & ( ) Pouco & ( ) Muito & ( ) NA & \\
\hline & ( ) Interromper estudos (devido à falta de renda) & ( ) Pouco & ( ) Muito & ( ) NA & \\
\hline & ( ) Problemas de convivência familiar & () Pouco & ( ) Muito & ( ) NA & \\
\hline & ( ) Não investimento em ensino profissionalizante & ( ) Pouco & ( ) Muito & ( ) NA & \\
\hline \multirow{5}{*}{$\begin{array}{l}\text { ( ) Atentado de } \\
\text { violência repentino na } \\
\text { residência/condomínio } \\
\text { (roubo, assalto, } \\
\text { agressão) }\end{array}$} & ( ) Sensação de insegurança & ( ) Pouco & ( ) Muito & ( ) NA & \\
\hline & ( ) Deixar de participar das atividades do bairro & ( ) Pouco & ( ) Muito & ( ) NA & \\
\hline & $\begin{array}{l}\text { ( ) Degradação de parte da residência (pelo ato } \\
\text { criminoso) }\end{array}$ & ( ) Pouco & ( ) Muito & () NA & \\
\hline & ( ) Deixar de conviver com vizinhos & ( ) Pouco & ( ) Muito & ( ) NA & \\
\hline & ( ) Gasto inesperado com medidas de segurança & ( ) Pouco & ( ) Muito & ( ) NA & \\
\hline \multirow{5}{*}{$\begin{array}{l}\text { ( ) Sensação de } \\
\text { insegurança }\end{array}$} & ( ) Não participação em atividades do bairro & ( ) Pouco & ( ) Muito & ( ) NA & \\
\hline & ( ) Não convivência com vizinhos & () Pouco & ( ) Muito & ( ) NA & \\
\hline & ( ) Não frequenta espaços públicos do bairro & ( ) Pouco & ( ) Muito & ( ) NA & \\
\hline & ( ) Mantém casa sempre fechada & ( ) Pouco & ( ) Muito & ( ) NA & \\
\hline & ( ) Problemas de saúde (transtornos psicológico) & ( ) Pouco & ( ) Muito & ( ) NA & \\
\hline \multirow[t]{2}{*}{ ( ) Isolamento social } & ( ) Não frequenta os espaços públicos/condomínio & ( ) Pouco & ( ) Muito & ( ) NA & \\
\hline & $\begin{array}{l}\text { ( ) Não desenvolvimento de relação social com os } \\
\text { vizinhos }\end{array}$ & ( ) Pouco & ( ) Muito & ( ) NA & \\
\hline
\end{tabular}

\section{Cálculo amostral}

A propósito do processo de recorte de amostras para aplicação de questionários, importa salientar que após levantamento das características dos dois conjuntos habitacionais sociais dos bairros Shopping Park e Mansour, em termos de: dados demográficos e socioeconômicos, equipamentos, inserção urbana, unidades habitacionais, impacto ambiental e energia, água, sistema de esgotos e custos (VILLA et al., 2017), foram escolhidos dois loteamentos considerados suficientemente representativos das características observadas:

(a) Residencial Sucesso Brasil - bairro Shopping Park; e

(b) Residencial Córrego do Óleo - bairro Mansour.

Considera-se que sua situação de relativa proximidade aos principais equipamentos públicos e privados de ambos os conjuntos, bem como em relação a uma área de proteção permanente, favorecerá a coleta de informações representativas sobre a realidade experienciada no conjunto. Posto isso, foi definido como universo para investigação os loteamentos: 1. Residencial Sucesso Brasil, composto de um total de 175 lotes; 2. Residencial Córrego do Óleo, composto de um total de 192 apartamentos.

Uma vez definida a população (ou universo) em 367 unidades, e objetivando aproximar-se do conhecimento de seus parâmetros (características que se desconhece), foi necessário definir uma amostra suficientemente representativa e capaz de fornecer estatísticas calculadas com certo grau de precisão e confiabilidade.

Decidiu-se pela definição estatística de uma amostra para o número de domicílios onde deverão ser aplicados os instrumentos de APO, considerando um erro amostral tolerável no valor de 0.05 , adotando o coeficiente de confiança de $95 \%$, conforme descrito a seguir.

Uma técnica muito utilizada no cálculo do tamanho de amostras para populações finitas consiste primeiramente em determinar um tamanho inicial n0, que pode ser visto como um grupo-alvo para servir de base estatística do cálculo do tamanho da amostra. Essa primeira aproximação é dada por:

$n_{0}=\frac{z_{1-\alpha}^{2} p(1-p)}{\epsilon_{0}^{2}}$

Em que:

$€ 0$ é o erro amostral tolerável;

$\alpha$ é o nível de confiança; e

Z1- $\alpha$ é o quantil da distribuição normal padrão de ordem $1-\alpha$.

152 Araujo, G. M.; Villa, S. B. 
O tamanho definitivo da amostra é determinado a partir da aproximação inicial, que determina o grupo-alvo. Como não é conhecida a proporção $\mathrm{p}$ de respostas para cada item do questionário, é aproximada a quantidade $\mathrm{p}(1-\mathrm{p})$. Como $0 \leq \mathrm{p} \leq 1$, então $\mathrm{p}(1-\mathrm{p}) \leq 1 / 4$. Assim,

$n_{0}=\frac{z_{1-\alpha}^{2}}{4 \epsilon_{0}^{2}}$

A fórmula para o cálculo amostral é dada por:

$\mathrm{N}=\frac{n \times n_{0}}{(n-1)+n_{0}}$

Em que:

N é o tamanho da população;

n0 é a primeira aproximação da amostra; e

n é o tamanho desejado da amostra.

Para aplicar instrumentos de avaliação pós-ocupação em dois loteamentos com 367 unidades (175 casas e 192 apartamentos), no bairro Shopping Park em Uberlândia, a amostragem é feita a partir de um erro amostral de 5\%, considerado tolerável.

Aqui, para o nível de confiança de $95 \%$ tem-se que $\mathrm{Z} 1-\alpha=1,96$. Para o erro amostral definido como N0 = 0.05 tem-se que a população inicial n0 é 96,04 $\approx 96$, de acordo com (2). Assim, de acordo com (3), sugere-se uma amostra de 188 domicílios.

Dessa forma, depreende-se que a aplicação de 188 questionários - sendo 90 casas térreas no Residencial Sucesso Brasil/bairro Shopping Park e 98 apartamentos do Residencial Córrego do Óleo/bairro Mansour compreenderá parcela suficientemente representativa de sua população, capaz de fornecer estatísticas representativas.

\section{Resultados e discussões}

Os resultados apresentados neste artigo dizem respeito aos dados coletados em uma unidade-caso caracterizada por casas térreas, o loteamento Sucesso Brasil (Figura 4).Os questionários foram aplicados no loteamento Sucesso Brasil, situado no bairro Shopping Park, na cidade de Uberlândia. O bairro é composto de quatorze empreendimentos, e o loteamento escolhido (Sucesso Brasil) possui 175 unidades habitacionais.

O conjunto é caracterizado por residências geminadas de área útil interna igual a $35 \mathrm{~m}^{2}$ (Figura 5), separadas por uma parede compartilhada entre os quartos e que não superam o forro em altura, ocasionando desconforto acústico e falta de privacidade, sendo esses os principais impactos relatados pelos moradores $(87,5 \%)$. Essas unidades não atendem a qualidade mínima exigida pela Norma de Desempenho - NBR 15575, em inúmeros itens. Foi detectado que a parede compartilhada entre as duas casas geminadas deveria apresentar um tratamento acústico de modo a garantir a não propagação de som entre as unidades.

Esse problema de acústica está ligado a alguns indicadores do $5 \mathrm{~W}$ - conectar, continuar aprendendo, tomar conhecimento e doar - uma vez que os ruídos podem gerar desentendimentos entre os vizinhos e interferir na privacidade do morador (85\%), impedindo suas atividades de concentração e autoconhecimento.

Devido à forma de implantação do PMCMV, com obras muitas vezes construídas em regiões periféricas da cidade por causa do baixo custo da terra (BIDERMAN et al., 2019), esses conjuntos HIS acabam carentes de infraestrutura e desconectados do restante da cidade. Esse tipo de impacto foi identificado pelos moradores respondentes, que sentem falta de conexão $(51,3 \%)$ e isolamento com relação ao restante da cidade $(48,8 \%)$, uma vez que o sistema de transporte público existente, que seria a forma de ligação/conexão para os moradores, é considerado por eles ineficiente (Figura 6).

O ideal seria que esses empreendimentos fossem implantados nas áreas centrais das cidades, em locais que apresentam vazios urbanos que apenas estão servindo para especulações imobiliárias, pois estariam próximas a áreas já consolidadas e com infraestruturas já existentes (BIDERMAN et al., 2019).

Tais impactos estão relacionados com os indicadores conectar, ser ativo e tomar conhecimento, uma vez que os moradores se sentem desconectados do restante da cidade, acabam negligenciando o uso das áreas 
públicas, usando somente o automóvel para chegar aos locais desejados, por meio de vias de fluxo rápido, e não percebem as paisagens da cidade em sua volta. Acabam, assim, não criando identidade com os locais por onde passam quase todos os dias.

Figura 4 - Localização do bairro Shopping Park

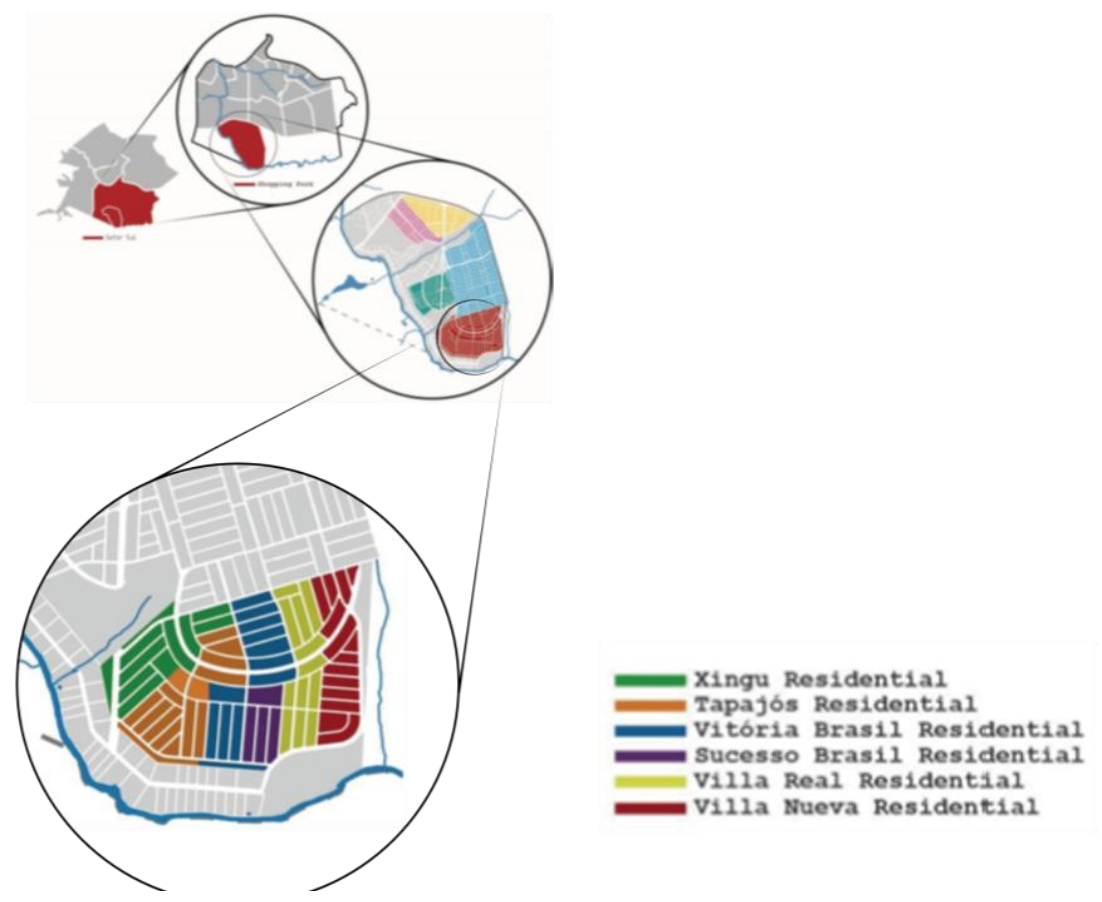

Fonte: Villa et al. (2017).

Figura 5 - Tipologia da unidade habitacional e foto das fachadas das unidades

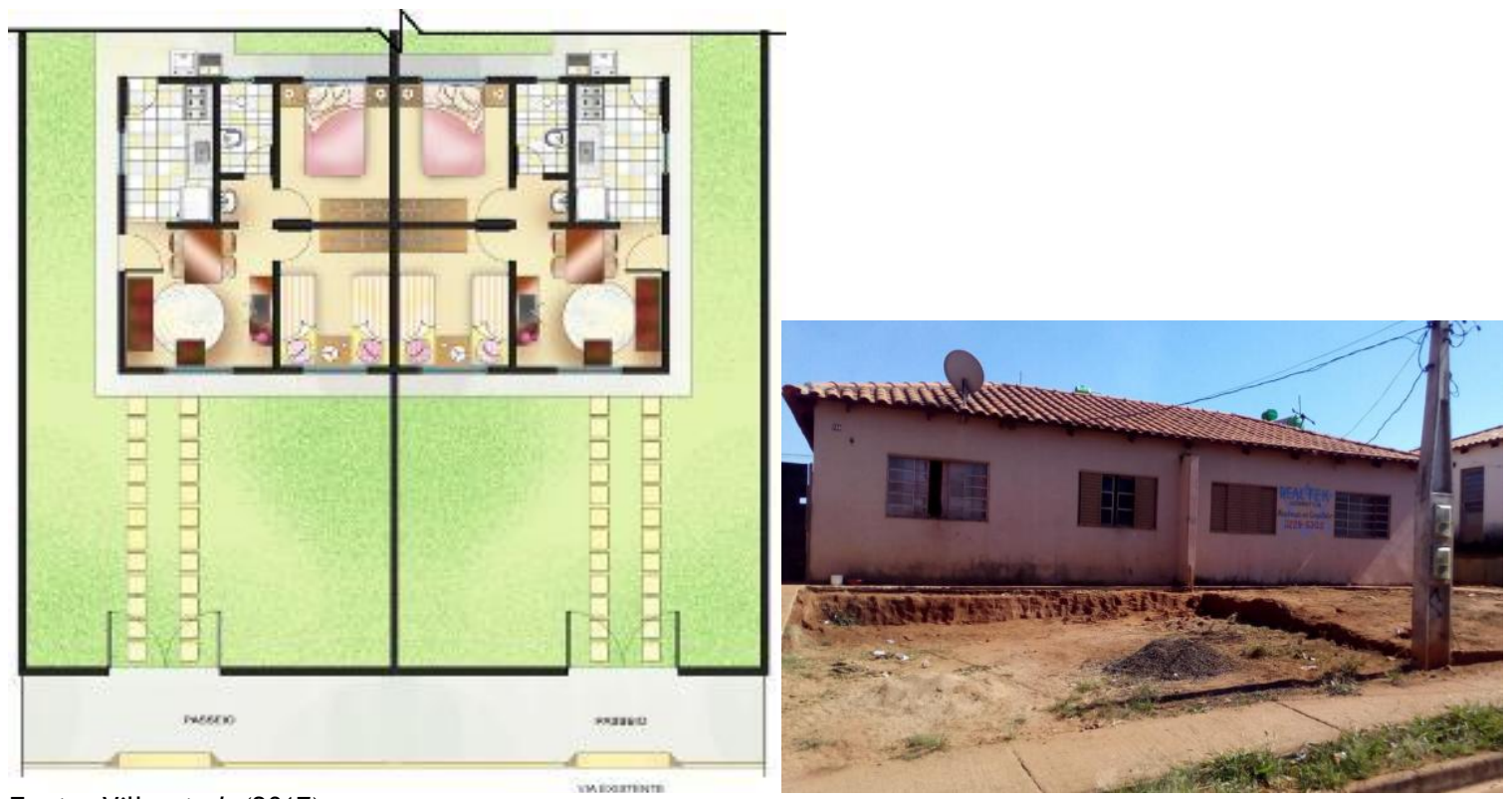

Fonte: Villa et al. (2017). 
Figura 6 - Nível de incômodo quanto à localização do conjunto

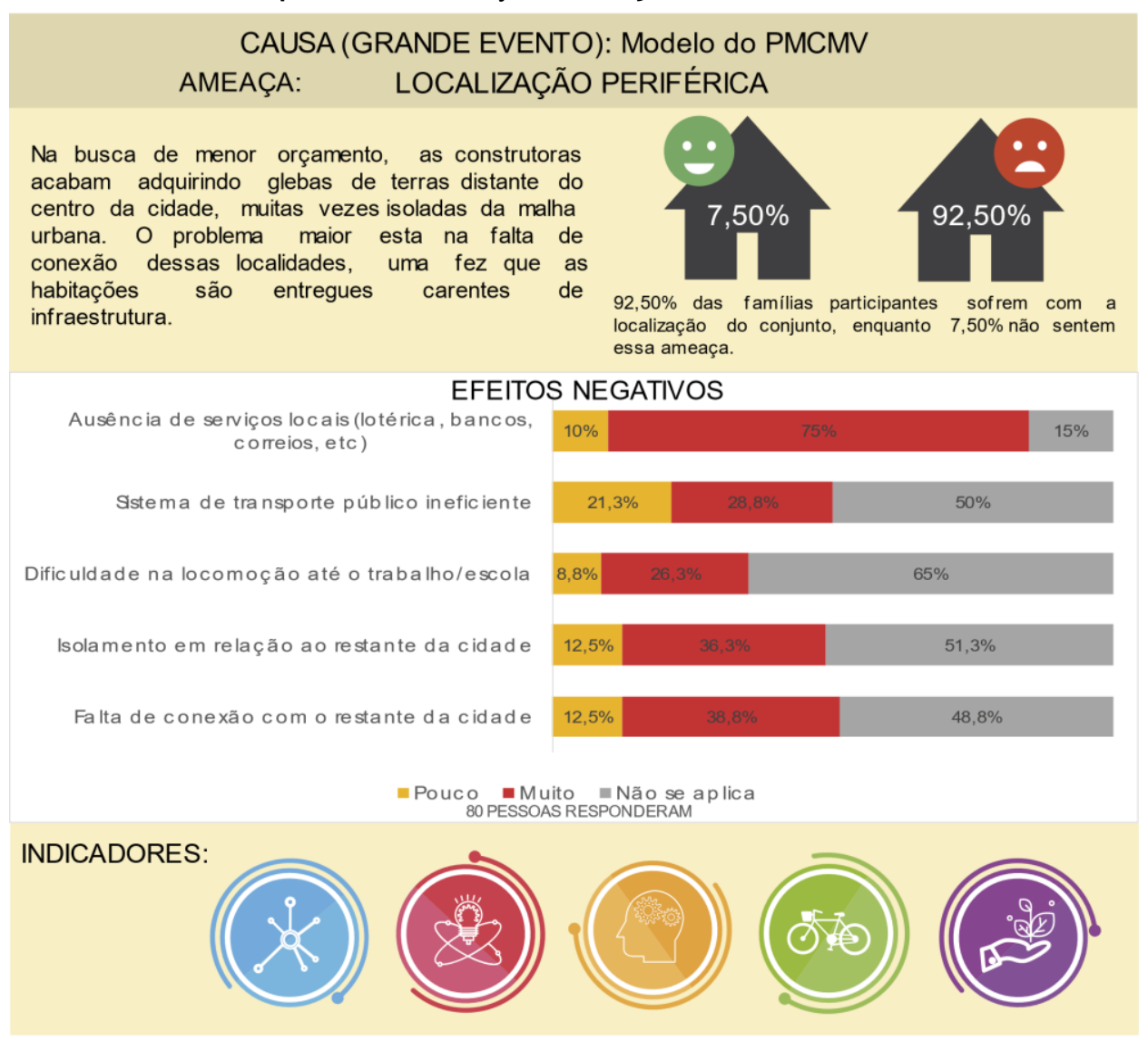

Outro problema identificado foi a falta de qualidade urbanística no bairro (Figura 7 e 8), onde as calçadas e ruas são desconfortáveis para andar, interferindo no indicador ser ativo, visto que os moradores não usam as ruas para caminhadas e desenvolvimento de atividades para saúde física, devido ao grande desnível, à descontinuidade da pavimentação e à falta de arborização (Figura9). Além de se sentirem inseguros nas poucas áreas de lazer existentes devido à prática de atividades ilícitas nesses locais (Figura 10), o que pode acabar levando à falta de convívio e a usos desses equipamentos e áreas públicas. Grande parte dos moradores acredita que se essas áreas públicas tivessem uma melhor qualidade, isso traria vitalidade urbana para o bairro, convidando-os a usufruir dos espaços públicos.

Lugares caminháveis são agradáveis, despertam percepção de segurança e oferecem destinos onde as pessoas querem estar. A maneira como as ruas (ambiente construído) são desenhadas afeta diretamente o estilo de vida, a saúde, a prática de atividades físicas e o bem-estar. Uma boa arborização deixa a temperatura amena e melhora a qualidade do ar, tornando o ato de caminhar mais agradável e convidativo. Calçadas amplas e bem iluminadas incentivam as pessoas a caminharem (ZUNIGA-TERAN et al., 2017; BAKER; STEEMERS, 2019).

Todos esses impactos relacionados à falta de qualidade urbanística das áreas públicas e até mesmo a própria falta de espaços públicos de lazer se relacionam diretamente com todos os indicadores do $5 \mathrm{~W}$, uma vez que os moradores acabam por se isolarem em suas casas e se sentem pouco à vontade a terem relações sociais com os vizinhos (conectar e doar), prejudicando o sentimento de identidade, sensação de pertencimento, com o bairro (tomar conhecimento). Não se sentem à vontade e seguros para usarem os equipamentos de lazer, desenvolver algumas das atividades, como praticar um esporte, ou somente caminhar nas ruas e calçadas (ser ativo, continuar aprendendo).

Os espaços públicos - ruas, calcadas, praças, parques, etc. -, que são projetos visando à escala humana, incentivam o uso desses espaços, potencializam as interações sociais entre vizinhos, que por sua vez é o que cria com o tempo a sensação de familiaridade e pertencimento a determinados locais, podendo assim elevar o senso de comunidade e contribuindo para o bem-estar dos moradores. 
Também se observa que, objetivando o atendimento às suas necessidades, os moradores realizam algum tipo de modificação e/ou melhorias utilizando recursos próprios, e essas reformas são feitas sem a assistência técnica especializada. Essa autoconstrução e a ausência de planejamento interferem no conforto e salubridade, tendo em vista o desperdício de material e a geração de rejeitos que acabam sendo despejados nas calçadas, ruas, lotes vagos, entre outros (Figuras 9 e 10).

\section{Figura 7 - Foto atual das fachadas do Residencial Sucesso Brasil}

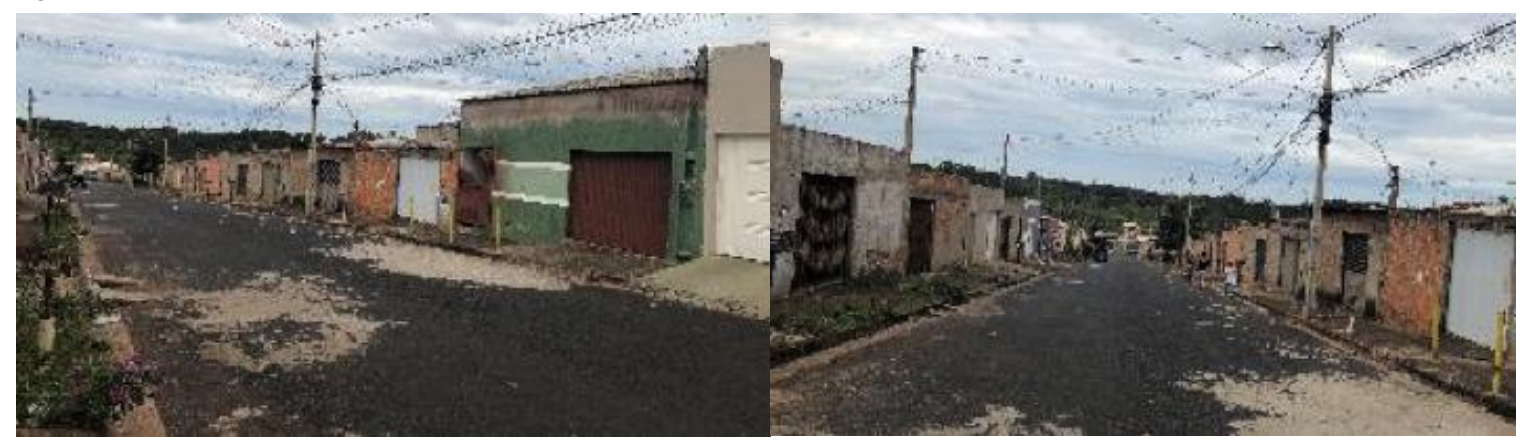

\section{Figura 8 - Fotos do estado das calçadas no conjunto}

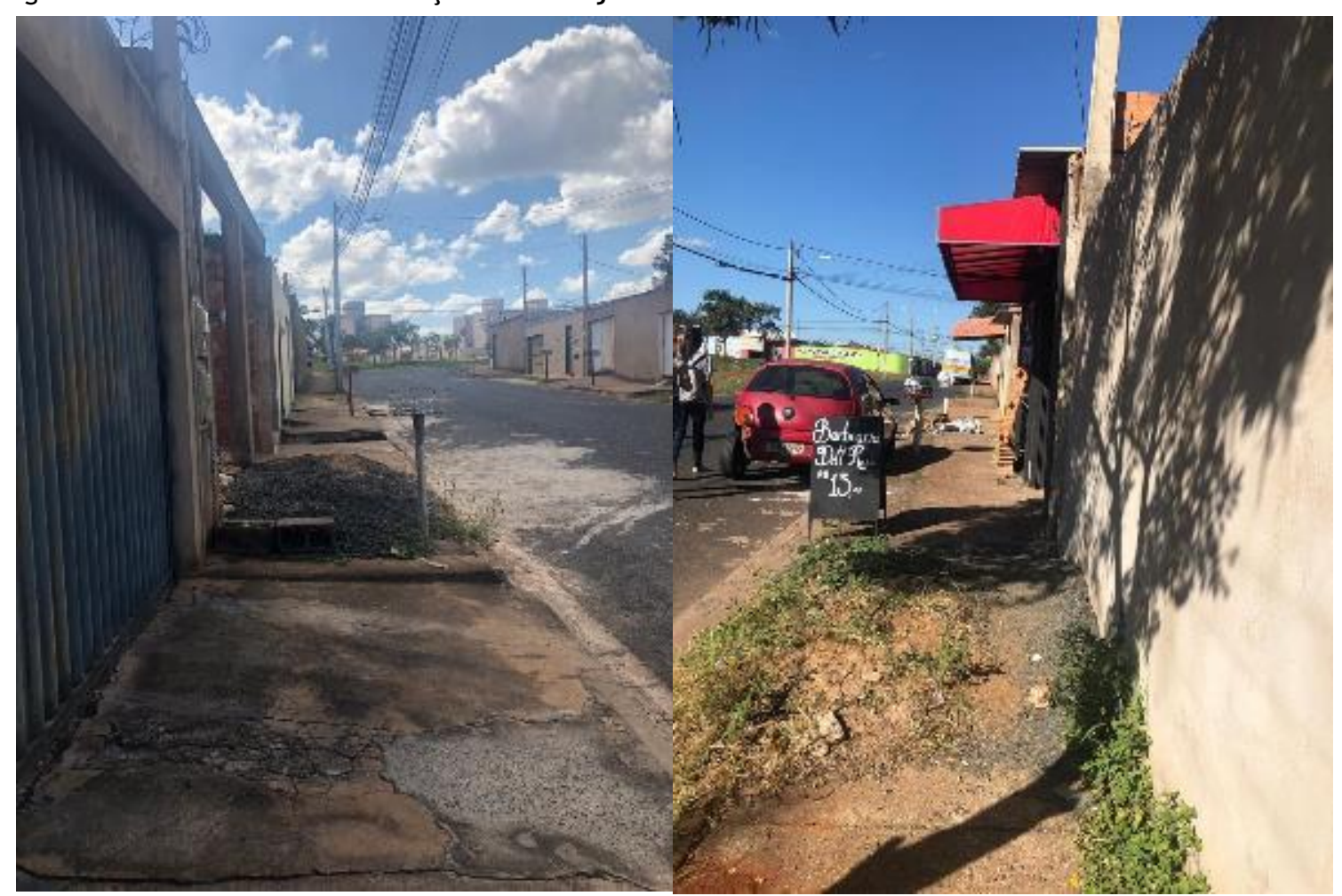

156 Araujo, G. M.; Villa, S. B. 
Figura 9 - Nível de incômodo em relação à qualidade das áreas públicas

\section{CAUSA (GRANDE EVENTO): APLICAÇÃO INCOMPLETA DO PMCMV AMEAÇA: Falta de qualidade nas áreas públicas}

Os conjuntos, na sua maioria, são entregues sem que as áreas públicas sejam finalizadas ou até mesmo construídas - escasses de equipamentos de lazer, falta de qualidade urbanisticas nas ruas e calçadas .

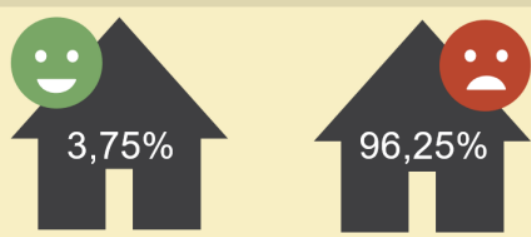

$96,25 \%$ das familias participantes se incomodam com a falta de qualidade das áreas públicas, enquanto $3,75 \%$ não sentem essa ameaça.

\section{EFEITOS NEGATIVOS}

Falta de arborização - sombrea mento

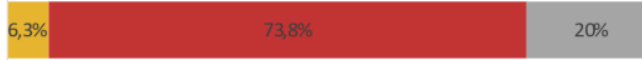

Não apropriação da calçada e rua (permanecer, conversar com o vizinho, etc

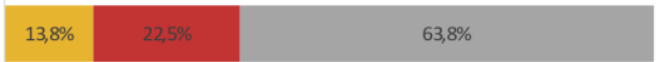

Ruase calçadas desconfortáveis para caminhas

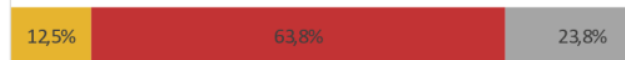

Dificuldade em andar de bicicleta (nas inadequadas, sinalização ruim, problema de trânsito)

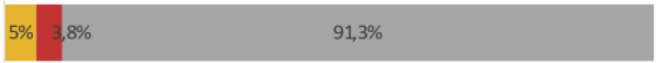

- Pouco muito = Não se ap lica
80 PESSOAS RESPONDERAM

\begin{tabular}{l|l|l|l} 
Necessidade de mudanças na reside ência (para sup rir falta de lazer) & $10 \%$ & $42,5 \%$ & $47,5 \%$
\end{tabular}

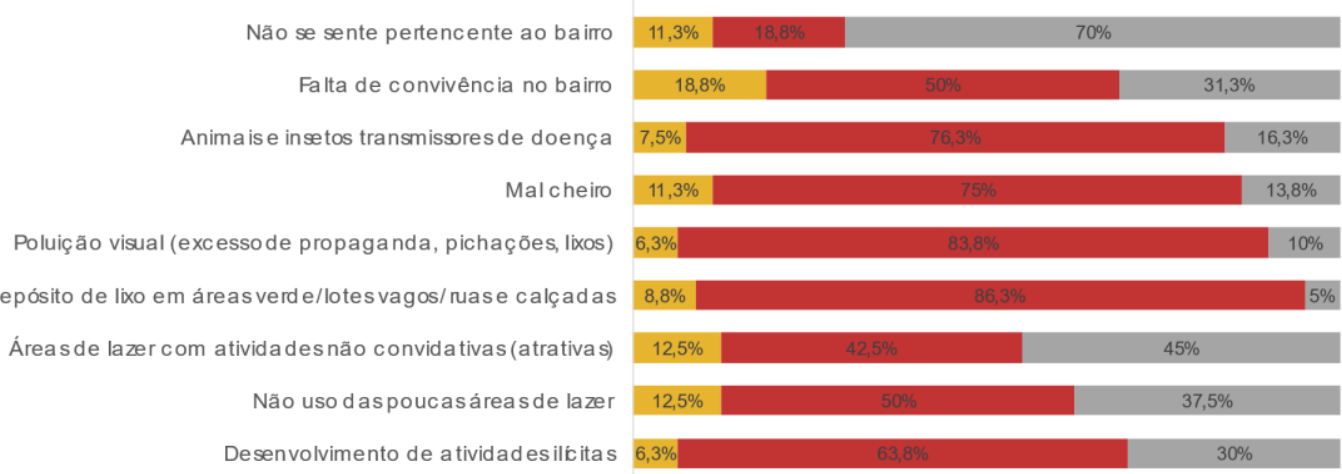

Pouco muito N Não se ap lica
80 PESSOAS RESPONDERAM

INDICADORES:
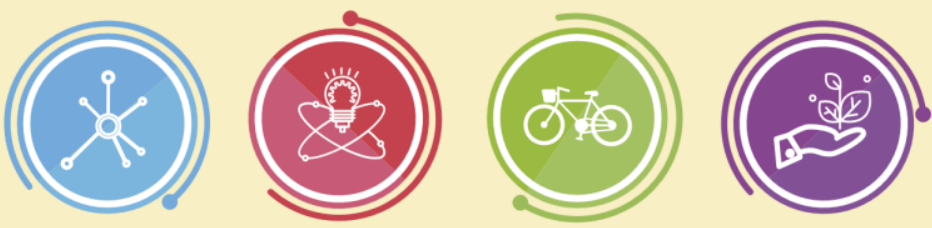
Figura 10 - Local separado para implantação de um praça que não foi construída

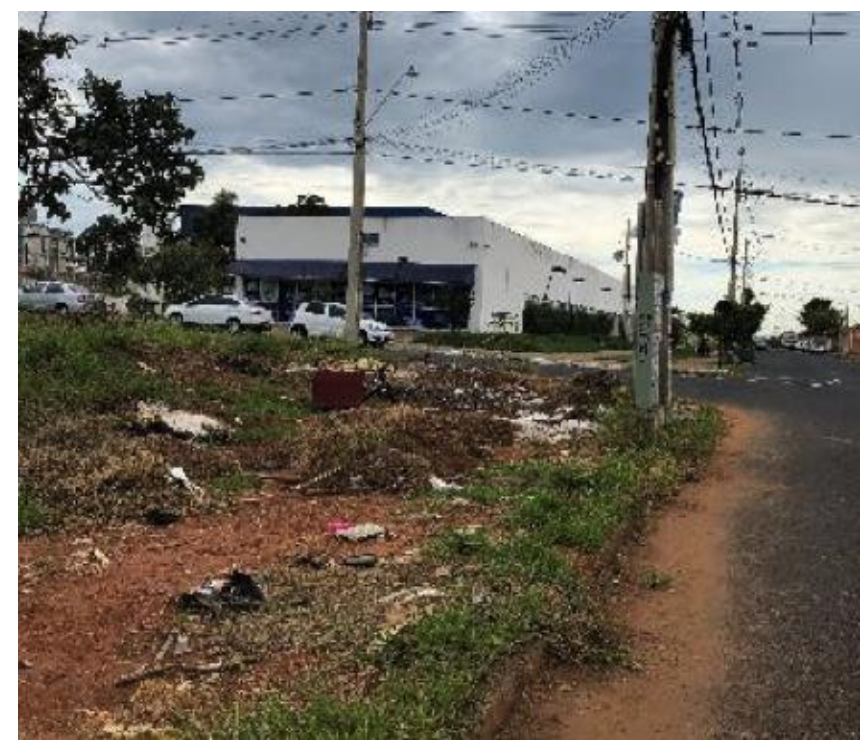

O MCMV apresenta como parâmetro de família a nuclear tradicional (pai, mãe e dois filhos), limitando assim as dimensões e compartimentação da casa. Esse fato gera insatisfação por parte dos moradores (73\% em relação ao tamanho dos cômodos e $72,5 \%$ consideram a quantidade de quartos insuficiente para o perfil familiar) (Figura 11), o que pode prejudicar diretamente o bem-estar dos usuários, já que os ambientes não atendem as suas reais necessidades (Figuras 12 e 13), uma vez que existem variados perfis de famílias (Figura 14).

O tamanho reduzido dos cômodos limita a convivência e o bom desempenho das atividades, uma vez que não há espaço suficiente para todos (VILLA et al., 2017), o que acaba prejudicando as relações familiares, que está ligada ao conectar, continuar aprendendo, tomar conhecimento indicadores do bem-estar, na medida em que começa a apresentar sobreposição de atividades nos ambientes, ou seja, desenvolvimento de atividades diferentes em um mesmo ambiente e períodos iguais (Figura 14).

É de extrema importância que as unidades habitacionais permitam uma adaptação e modificação por parte dos moradores para atender as suas reais necessidades a cada fase de sua vida - da infância à velhice - além de proporcionar um controle sobre os espaços onde vivem, permitindo assim a sensação de familiaridade e pertencimento.

A partir dessa análise alguns tipos de sobreposição de atividades (Figura 15) interferem diretamente no indicador conectar, desenvolvendo um ambiente estressante e com pouca conexão entre os moradores (família) e pouca privacidade, o que está ligado ao indicador tomar conhecimento, visto que pela falta de espaço pode interferir no seu desenvolvimento pessoal de forma negativa.

Os resultados da aplicação do questionário de impacto também reforçam teorias que indicam que o espaço possui uma relação íntima com os seus usuários, mesmo que estes não percebam. Autores indicam que é fundamental que o ambiente esteja de acordo com as necessidades dos usuários (ORNSTEIN, 2005), entretanto muitas vezes um ambiente pode estar atendendo a sua função e o usuário não se sentir bem no local.

A habitação, tanto sua localização quando a própria edificação,tem influência em todos os aspectos da vida de seus moradores, desde quão bem podem dormir, com que frequência encontram com amigos e quão seguros sentem-se, visto que é o lugar onde as pessoas passam maior parte de seu tempo (WHEELER; HUGGETT; ALKER, 2016).

Segundo autores, existem trabalhos que estabelecem vínculos diretos entre uma habitação precária e baixa noção de bem-estar. Nesse sentido pode-se concluir que casas com elevada qualidade arquitetônica e funcionalidade podem proporcionar melhora significativa no bem-estar de seus usuários. 
Figura 11 - Nível de insatisfação em relação aos tamanhos dos cômodos

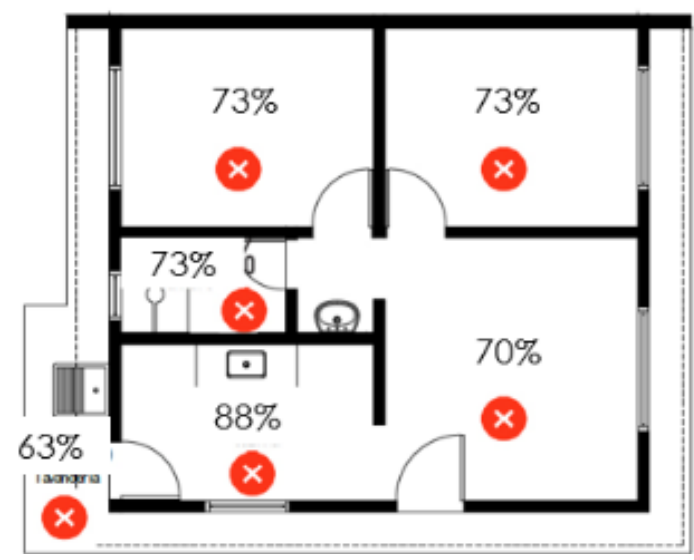

Figura 12 - Foto de um quarto de uma das residências (esquerda); foto de um quarto em uma residência ampliada (direita)
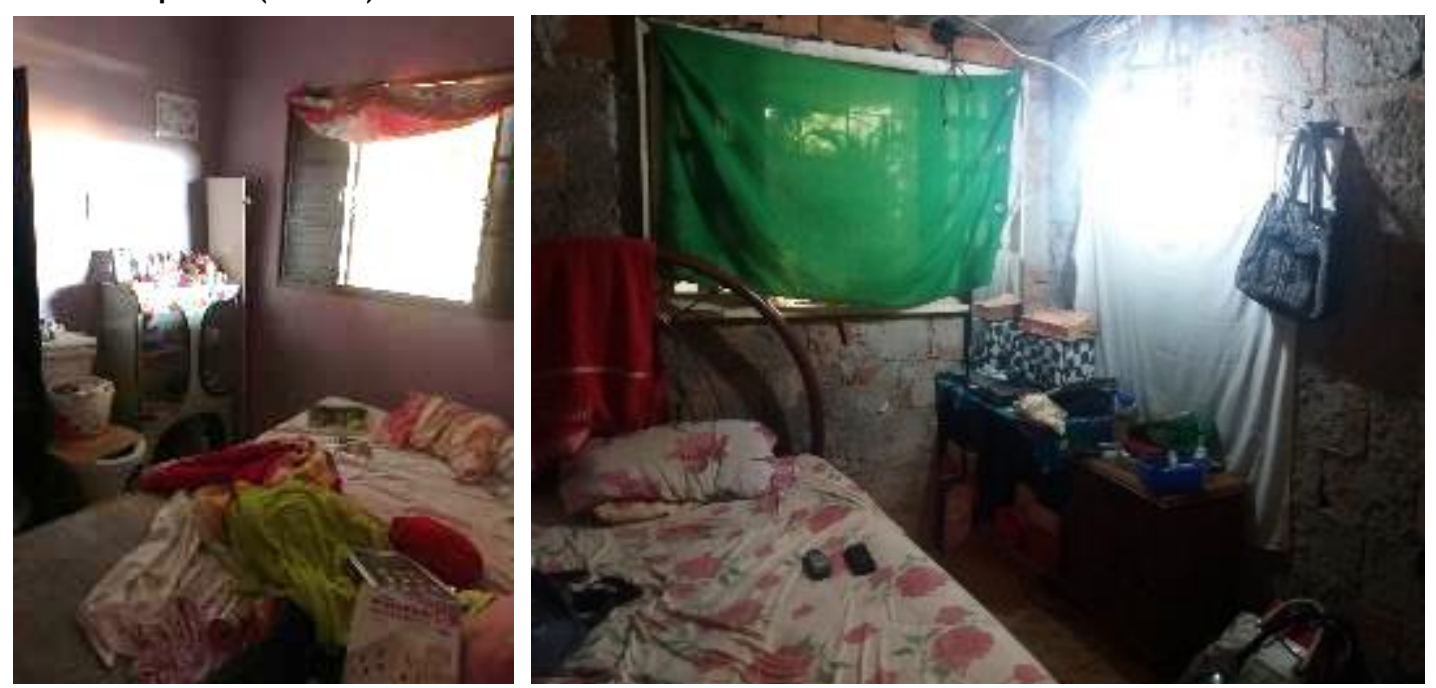

Fonte: Villa et al. (2017).

Figura13 - Sala de uma das residências

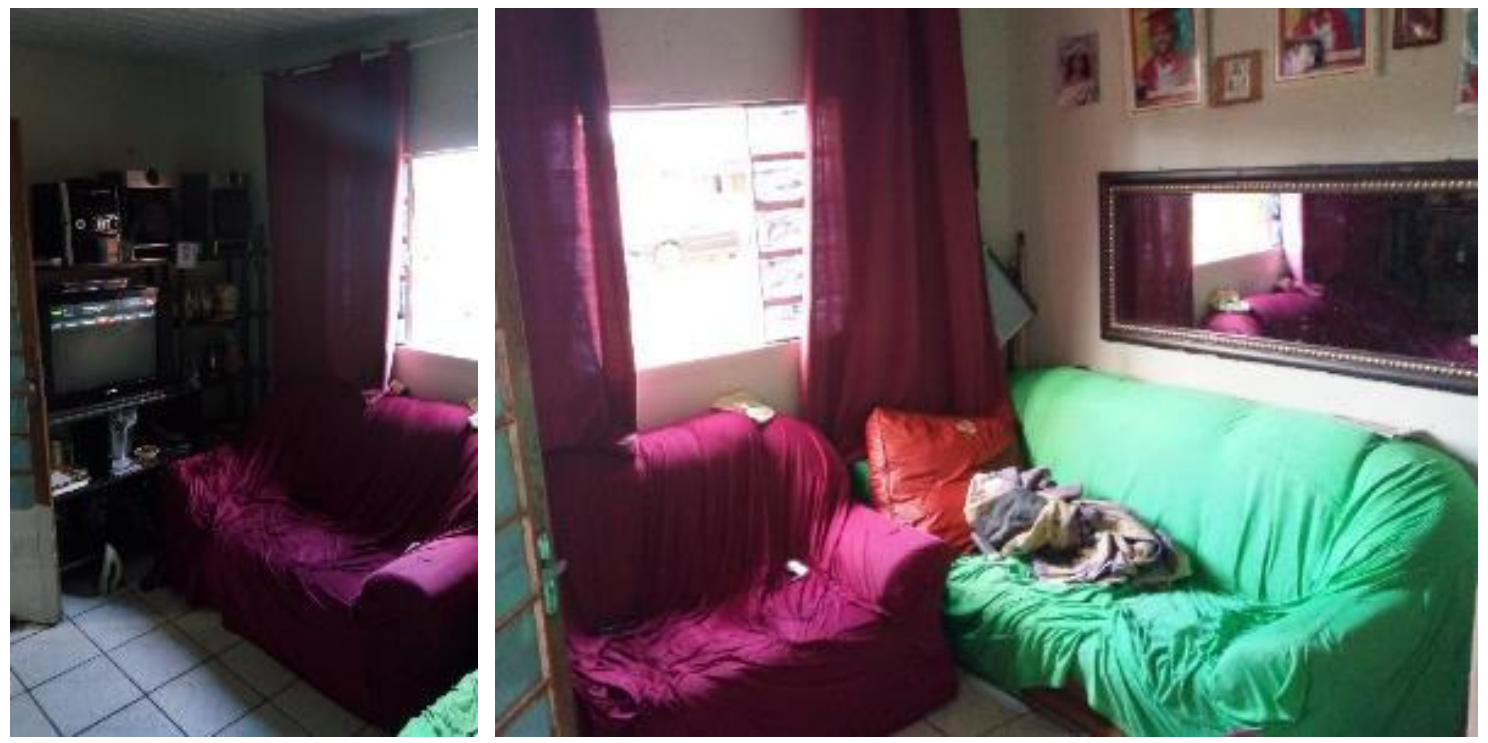

Fonte: Villa et al. (2017). 
Figura14 - Nível de incômodo em relação ao tamanho dos cômodos da unidade habitacional

$$
\begin{aligned}
& \text { CAUSA (GRANDE EVENTO): Modelo do PMCMV } \\
& \text { AMEAÇA: REDUÇÃO DAÁREA RESIDENCIAL }
\end{aligned}
$$
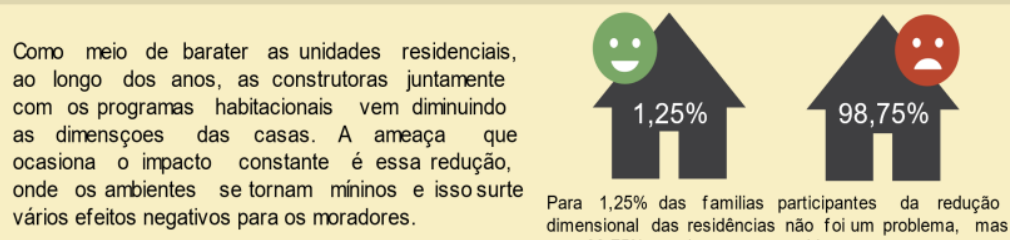
dimensional das residências não foi um problema, ma para $98,75 \%$ consiste em um problem

EFEITOS NEGATIVOS

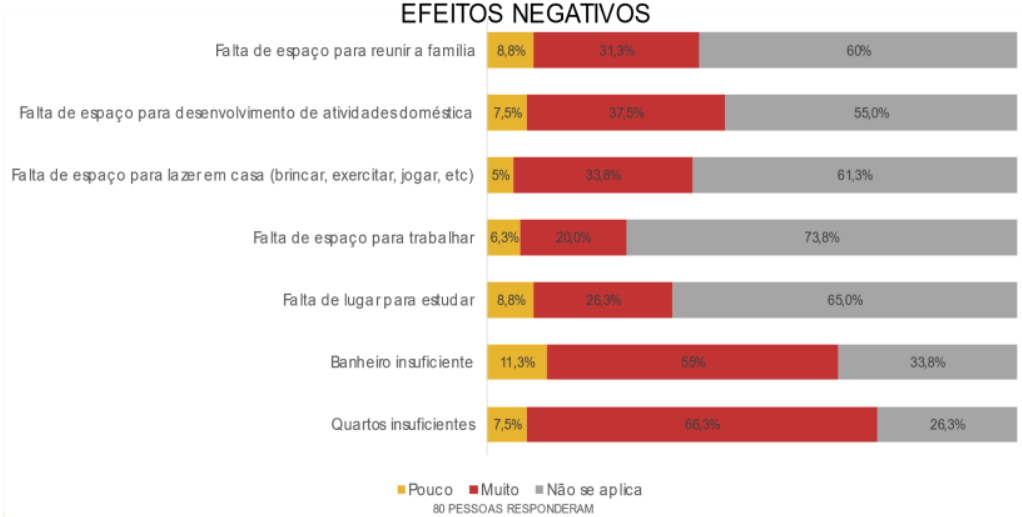

INDICADORES:

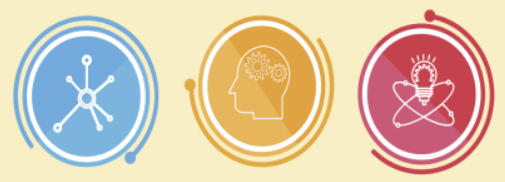

Figura 15 - Nível de incômodo em relação à sobreposição de atividades em mesmo cômodo

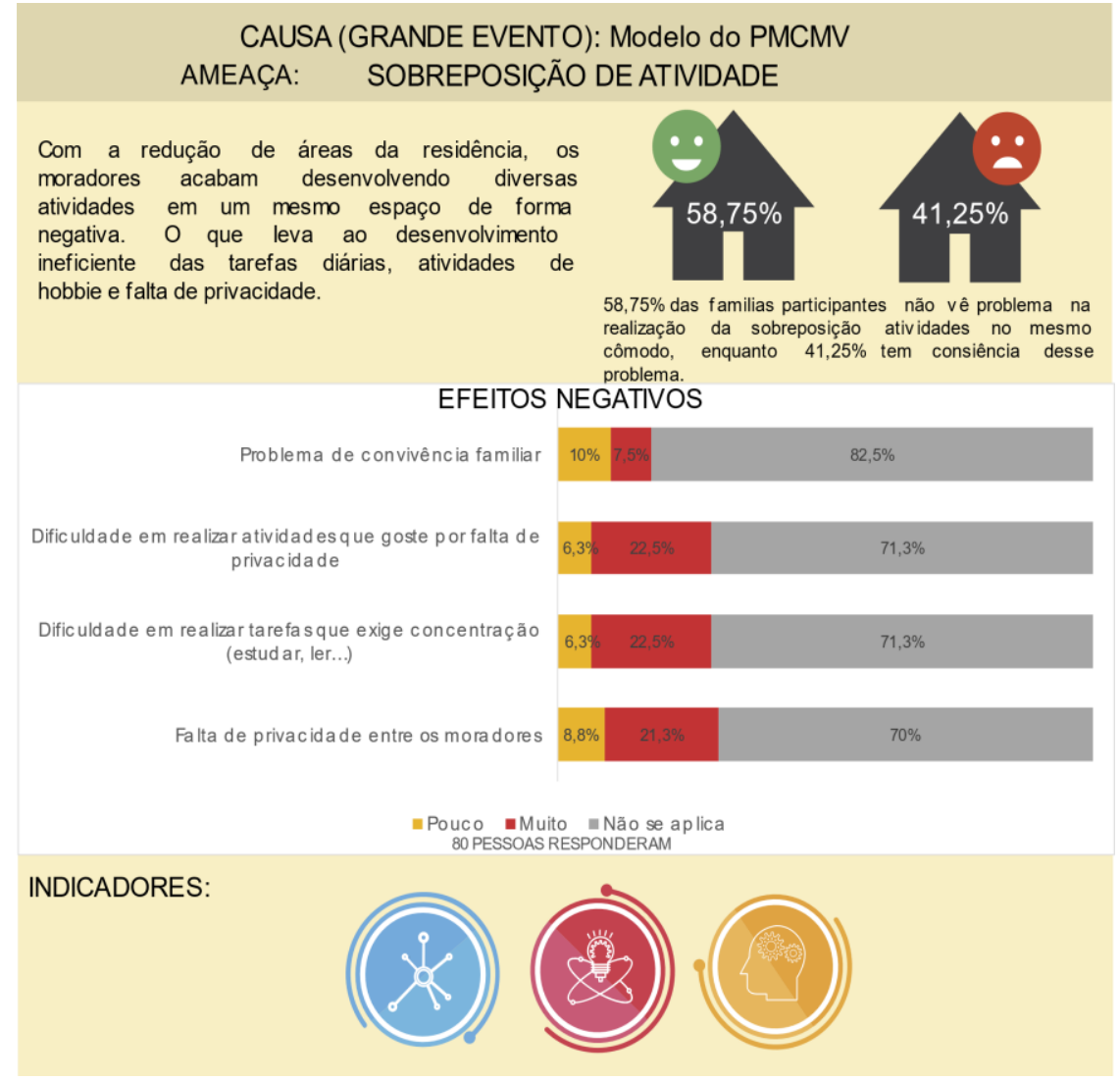

160 Araujo, G. M.; Villa, S. B. 
Contudo, essas evidências são pouco ou quase nada consideradas nos empreendimentos do programa MCMV. A avaliação de impacto realizada no estudo de caso confirma que a unidade habitacional (projeto idealizado pelo PMCMV) demonstra ser pouco resiliente frente aos inúmeros e variados impactos que incidem sobre ela.

\section{Conclusões}

É possível notar a partir de alguns dos resultados até o presente momento da pesquisa, sob a ótica dos $5 \mathrm{~W}$, a existência de princípios de resiliência, por parte dos moradores nas habitações no Shopping Park, uma vez que mesmo diante de suas limitações acabam adaptando-se nos ambientes em busca de melhorar o seu bemestar. Porém, nem sempre suas necessidades são satisfeitas após tais modificações, pois surgem novos problemas devido à realização de intervenções sem assistência técnica qualificada, podendo perceber que o ambiente construído das unidades habitacionais não permite de forma satisfatória o desenvolvimento dos $5 \mathrm{~W}$ geradores de bem-estar.

A adoção do modelo de análise britânico evidenciou as conhecidas limitações das habitações produzidas pelo PMCMV excessivamente já discorrida pela comunidade cientifica, podendo dessa forma confirmar as piores expectativas sobre a qualidade das produções habitacionais na realidade brasileira, por meio dos estudos na cidade de Uberlândia.

Nota-se aqui a importância de um ambiente resiliente que permita diferentes configurações, visto que existem diferentes perfis de usuários e diversas realidades. Esse fato torna-se altamente importante em um contexto de mudanças, sejam elas climáticas, demográficas ou de modo de vida. O ambiente construído pode e deve responder de forma positiva as necessidade e desejos dos usuários.

Entendendo, assim, que o ambiente construído interfere diretamente no bem-estar dos moradores, a pesquisa de mestrado vê a necessidade de investigar o bem-estar dos moradores por meio dos indicadores dos $5 \mathrm{~W}$, a fim de entender como o ambiente construído pode proporcionar bem-estar, de modo que possa desenvolver soluções e estratégias direcionadas aos moradores que contemplem $5 \mathrm{~W}$ gerando bem-estar e espaços mais resilientes.

Estima-se, a partir dos resultados obtidos, o desenvolvimento de ferramentas computacionais (aplicativo e/ou página na Web) destinadas aos usuários, afim de orientar estratégias que contemplem os $5 \mathrm{~W}$ para obtenção de um melhor bem-estar, consequentemente ambientes mais resilientes, e principalmente promover real mudança na qualidade de vida desses usuários. Também se pretende contribuir para as recomendações globais da New Urban Agenda - Habitat III - e SustainableDevelopmentGoals- AGENDA 2030 -, e orientações locais do Ministério das Cidades, fornecendo subsídios para a elaboração de projetos habitacionais de interesse social mais resilientes, estabelecendo sua relação com o bem-estar dos moradores. Além disso, o trabalho avança no desenvolvimento de instrumentos de avaliação e análise do bem-estar e da resiliência no ambiente construído.

A pesquisa pretende avançar na área em três medidas principais:

(a) analisar o bem-estar como um atributo da resiliência no ambiente construído focado no ponto de vista do usuário-morador e sua capacidade adaptativa;

(b) desenvolver instrumentos computacionais tecnológicos e aplicativos de APO para sua análise e disponibilização dos resultados; e

(c) contribuir de forma prática e direta ao usuário e sua assistência técnica para melhoria do bem-estar (5W) ampliando a resiliência.

\section{Referências}

AKED, J.; THOMPSON, S. 'Five ways to wellbeing: new applications, new ways of thinking', in which this project features as a 'case study'. July 2011. Disponível em: https://neweconomics.org/2011/07/fiveways-well-new-applications-new-ways-thinking. Acesso em: 5 nov. 2018.

AMORE, C. S.; SHIMBO, L. Z.; RUFINO, M. B. (org). Avaliação do Programa Minha Casa Minha Vida em seis estados brasileiros. Rio de Janeiro: Letra Capital, 2015.

ANDERSON, J. et al. Lively social space, well-beingactivity, andurban design: findingsfrom a lowcostcommunity-ledpublicspaceintervention. Longon: Sage, 2016. 
ANGÉLIL, M.; HEHL, R. (ed.). Minha Casa-NossaCidade: innovating mass housing in Brazil.Berlin: ETH Zurich, 2014.

ARUP; THE ROCKEFELLER FOUNDATION. City Resilience Index, 2015.Disponívelem:

https://www.arup.com/perspectives/publications/research/section/city-resilience-index. Acesso em: 15 set. 2019.

BAKER, N.; STEEMERS, K. Healthy homes: designingwith light andair for sustainabilityandwellbeing. London. London: RIBA Publishing, 2019.

BIDERMAN, C. et al. Morar longe: o Programa Minha Casa Minha Vida e a expansão das Regiões Metropolitanas. Relatório: São Paulo: CEPESP/FGV; Instituto Escolhas, 2019.

BRAND, S. HowBuildingsLearn: whathappensafterthey'rebuilt. New York: Penguin, 1994.

BROOKS, N. Vulnerability, riskandadaptation: a conceptual framework. WorkingPaper 38, Tyndall Centre for ClimateChangeResearch, UniversityofEastAnglia, Norwich. 2003.

COLE, R. J. Building environmental assessment methods: redefining intentions and roles. Building Research \& Information, v. 33, n. 5, p. 455-467, 2005.

DRESCH, A.; LACERDA, D. P.; JUNIOR, J. Design Science Research: método de pesquisa para avança da ciência e tecnologia. Porto Alegre: Bookman, 2015.

ELIAS-TROSTMANN, K. et al. Mais fortes que a tempestade: aplicando a avaliação de resiliência comunitária urbana aos eventos climáticos extremos. World Resources Institute, 2018.

ÉPOCA Negócios. Brasil tem 230 milhões de smartphones em uso. 2019. Disponível em: https://epocanegocios.globo.com/Tecnologia/noticia/2019/04/brasil-tem-230-milhoes-de-smartphones-emuso.html. Acesso em: 15 fev. 2020.

FENTON, M. et al. ClimatechangeandtheGreatBarrierReef: industries andcommunities. In: JOHNSON, J. E.; MARSHALL, P. A. (ed.).Climatechangeandthegreatbarrierreef: a vulnerabilityassessment. Australia:GreatBarrierReef Marine Park AuthorityandAustralianGreenhouse Office, 2007.

GARCIA, E. J.; VALE, B. Unravelling sustainability and Resilience in the environment. New York: Routledge, 2017.

HOLLING, C. S. Resilienceandstabilityofecological systems. In: ANNUAL reviewofecologyandsystematics. Luxemburg: InternationalInstitute for Applied Systems Analysis, 1973.

IBGE EDUCA. Uso de internet, televisão e celular no Brasil. 2017. Disponível em:

https://educa.ibge.gov.br/jovens/materias-especiais/20787-uso-de-internet-televisao-e-celular-no-brasil.html. Acesso em 15 fev. 2020.

INTERGOVERNMENTAL PANEL ON CLIMATE CHANGE. Climate change 2014: impacts, adaptation and vulnerability. Contribution of Working Group II to 241 the Fifth Assessment Report of the Intergovernmental Panelon Climate Change. Cambridge: Cambridge University Press, 2014.

KOWALTOWSKI, D. C. C. K. et al. A criticalanalysisofresearchof a mass-housingprogramme. Building Research \& Information, v. 47, n. 6, p. 716-33. 2019.

LEMOS, M. F. Sustentabilidade e resiliência. In: ENANPARQ. ARQUITETURA, CIDADE E PROJETO: UMA CONSTRUÇÃO COLETIVA, 3., São Paulo, 2014. Anais [...] São Paulo: ANPARQ, 2014.

MAGUIRE, B.; CARTWRIGHT, S. Assessing a community's capacity to manage change: a resilience approach to social assessment. Canberra: Australian Government Bureau of Rural Sciences, 2008.

MALLORY-HILL, S.; PREISER, W. F. E.; WATSON, C. (ed.). Enhancing building performance. Oxford: Wiley-Blackwell, 2012.

MEEROW, S.; NEWELL, J. P. Resilience and complexity: a bibliometric review and prospects for industrial ecology. Journalof Industrial Ecology, v. 19, n. 2, p. 236-251, 2015.

ONO, R. et al. Avaliação Pós-Ocupação: na arquitetura, no urbanismo e no design: da teoria à prática. São Paulo: Oficina de Texto, 2018.

ORNSTEIN, S. W. Arquitetura, Urbanismo e Psicologia Ambiental: uma reflexão sobre dilemas e possibilidades da atuação integrada. Revista Psicologia USP, São Paulo, v. 16, n. 1/2, p. 155-165, 2005. 
ORNSTEIN, S. W.; VILLA, S. B. (org.). Qualidade ambiental na habitação: avaliação pós-ocupação. São Paulo: Oficina de Textos, 2013.

PICKETT, S. T. A.; CADENASSO, B. M. M. L.; FELSON, A. J. Ecological resilience and resilient cities.Building Research \& Information,v. 42, n. 2, p. 143-157, 2014.

PREISER, W. F. E.; VISCHER, J. C. (ed.). Assessingbuilding performance. Oxford: Elsevier, 2005.

STEEMERS, K. Architecture for well-being and health. Daylight \& Architecture, Jul. 2015. Disponível em: http://thedaylightsite.com/architecture-for-well-being-and-health/. Acesso em: 15 set. 2019.

STEVENSON, F.; BARBORKSA-NAROZNY, M. Technical and social redundancy for low carbon living. In: ARCHITECTURE AND RESILIENCE ON A HUMAN SCALE CONFERENCE, Sheffield, 2015. Proceedings [...] Sheffield, 2015.

THALER, R. H.; SUNSTEIN, C. R. Nudge: improving decisions about health, wealth, andhappiness. Yale University Press, 2008.

VILLA, S. B. et al. Método de análise da resiliência e adaptabilidade em conjuntos habitacionais sociais através da avaliação pós-ocupação e coprodução. Uberlândia: Universidade Federal de Uberlândia, Universidade de Sheffield, 2017. Relatório Final de Pesquisa.

VILLA, S. B.; ORNSTEIN, S. W. (org.). Qualidade ambiental na habitação: avaliação pós-ocupação. São Paulo: Oficina de Textos, 2013.

VILlA, S. B.; SARAMAGO, R. C. P.; GARCIA, L. C. Avaliação Pós-Ocupação no Programa Minha Casa Minha Vida: uma experiência metodológica. Uberlândia: Universidade Federal de Uberlândia, 2015.

WHEELER, J.; HUGGETT, E.; ALKER, J. Health andwellbeing in homes. UK Green Building Council and The Building Centre, 2016.

YIN, R. K. Estudo de caso: planejamento e métodos. 3. ed. Porto Alegre: Bookman, 2005.

ZUNIGA-TERAN, A. A. et al. Neighborhood design, physicalactivity, andwellbeing: applying the walkabilitymodel. International Journalof Environmental Research and Public Health, v. 14, n. 1, p. $76,2017$.

\section{Agradecimentos}

Agradecimentos às instituições CNPq, Fapemig, Capes e UFU, que apoiam e viabilizam esta pesquisa. Agradeço também a todos os colegas que ajudaram na aplicação dos questionários, principalmente a Fernanda Vilela e Paula Vasconcelos, colegas pesquisadoras envolvidas no Grupo [MORA].

\section{Geovanna Moreira Araujo}

Programa de Pós-Graduação em Arquitetura e Urbanismo | Universidade Federal de Uberlândia | Av. João Naves de Avila, 2121, Bloco 1l, Sala 236 | Uberlândia - MG - Brasil | CEP 38400-902 | Tel.: (34) 32394058 | E-mail: geovannaraujo@gmail.com

Simone Barbosa Villa

Programa de Pós-Graduação em Arquitetura e Urbanismo | Universidade Federal de Uberlândia | E-mail: simonevilla@ufu.br

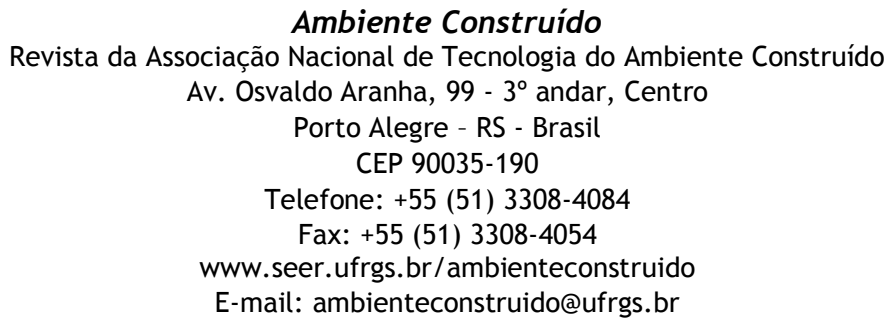

